
\title{
R Research Soure \\ Out-of-sample Predictability of Economic Efficiency Measures of U.S. Banks: Evidence of capital adequacy requirements
}

Kekoura Sakouvogui ( $\nabla$ sakouvoguikekoura@yahoo.com )

U.S Census Bureau Washington D.C

Research Article

Keywords: SVR, DEA, U.S banks, Economic efficiency measures, Out- of-sample predictability

Posted Date: November 23rd, 2020

DOI: https://doi.org/10.21203/rs.3.rs-57468/v2

License: (c) (i) This work is licensed under a Creative Commons Attribution 4.0 International License.

Read Full License 


\title{
Out-of-sample Predictability of Economic Efficiency Measures of U.S. Banks: Evidence of capital adequacy requirements
}

\author{
Kekoura Sakouvogui, $\mathrm{PhD}$ * \\ Mathematical Statistician Researcher \\ Decennial Statistical Studies Division \\ United States Census Bureau \\ Washington, DC 20746
}

November 14, 2020

\begin{abstract}
This paper contributes to the sparse debate on the effect of capital adequacy requirements on banks' economic efficiency measures. Precisely, we evaluate the out-of-sample predictability of capital adequacy requirements on banks' economic efficiency measures using Support Vector Regression (SVR) model with Linear, Polynomial and Radial Basis Function kernels and ordinary least squares (OLS) model. This analysis is important because a prediction of economic efficiency measures allows for an untangle view of bank's progress that is useful for management as it gains a high degree of transparency in the evaluation of future events. Our framework adapts optimization of h-block cross-validation to account for serial correlation of economic variables to produce robust sets of tuning parameters for SVR model. Using a total of 10,380 December quarterly observations of U.S Commercial and Domestic banks spanning from 2008 through 2019, empirical results show that SVR model provides better benchmarking insights in the evaluation of economic efficiency measures compared to the OLS model. Furthermore, in contrast to previous approaches identifying a single "best" model among competing models, the results of Model Confidence Test suggests that the out-of-sample forecasting confidently identifies superior predictive accuracy of SVR model-based forecasts over OLS model.
\end{abstract}

Keywords: SVR, DEA, U.S banks, Economic efficiency measures, Outof-sample predictability JEL classification: C01, C18, C52, Q11.

${ }^{*}$ The views set forth are those of the author and do not indicate concurrence by the United States Census Bureau nor the Department of Commerce. Email: sakouvoguikekoura@yahoo.com. 


\section{Introduction}

Over recent years, the banking sector has undergone enormous changes and thus, the role of capital adequacy requirements has turned out to be more complex due to the economic liberalization. Due to this phenomenon, literature has presented a two-step approach in the evaluation of capital adequacy requirements on economic efficiency measures of banks in which the specification of cost function is required (Pessarossi and Weill, 2015 and Sakouvogui and Shaik, 2020).

First, using the linear programming Data Envelopment Analysis (DEA) of Charnes et al. (1978) and Banker et al. (1984), economic efficiency measures are estimated based on the selected input and output variables pertinent to the intermediate approach (cost function). Second, the relationship between capital adequacy requirements and economic efficiency measures, treated as the dependent variable, is evaluated using either the Tobit model or Ordinary Least Squares (OLS) model (Barth et al. 2004; Hoff, 2007; Hwang and Kao, 2008; Pasiouras et al. 2009; Barth et al. 2013; and Sakouvogui and Shaik, 2020). Empirical studies have found that capital adequacy requirements is one of the most direct contributors to financial stability; see for example, Pasiouras et al. (2009); Gorton and Metrick, (2010); Chortareas, et al. (2012); Barth et al. (2013); Dong et al. (2014); Pessarossi and Weill, (2015); Sakouvogui and Shaik, (2020); and Sakouvogui, (2020a) ${ }^{1}$

These contributors are motivated in part by the primary effect of capital adequacy requirements and its influence on banks' economic efficiency measures (Pessarossi and Weill, 2015). Various papers have concluded that banks operate in heavily regulated sector (Barth et al. 2004; Pasiouras et al. 2009; and Barth et al. 2013) with two diverging views of capital adequacy requirements (Barth et al. 2013; Pessarossi and Weill, 2015; and Sakouvogui, 2020b). One strand of literature has found a positive effect of capital adequacy requirements on banks' efficiency measures (Holmstrom and Tirole, 1997 and Mehran and Thakor, 2011). In contrast, another strand of literature has suggested a negative effect of capital adequacy requirements on banks' performance measures (Berger and Bonaccorsi, 2006; Pasiouras et al. 2009; Pesssarossi and Weill, 2015; and Sakouvogui and Shaik, 2020). Henceforth, with these divergent views of the debate, determining the impact of capital adequacy requirements on economic efficiency measures of banks has become a paramount and popular question in the literature (Pessarossi and Weill, 2015 and Sakouvogui and Shaik, 2020), and therefore, further investigations are needed.

While the empirical technique of the second step in a two-step approach is maximum likelihood estimation of a Tobit or OLS model, Hoff (2007) and Hwang and Kao (2008) have concluded that the OLS model should replace the Tobit model as a sufficient second step in a two-step approach. However, in applying the OLS model, very little is known about the prediction in real-time of economic efficiency measures; some prominent examples include Casu and Girardone (2002), Drake et al. (2006), Barth et al. (2013), Thagunna and Poudel (2013), Dong et al. (2014), Rosman et al. (2014), and Assaf et al. (2019).

\footnotetext{
${ }^{1}$ The most recent financial crisis has revealed the importance of bank's regulations and capital adequacy requirements as financial factors. The assumption of capital adequacy requirements is that each bank must meet the minimum capital requirement imposed by the regulatory authority which depends on the characteristics of bank' assets.
} 
The apparent limitation of recent studies, known as the failure to determine the out-of-sample predictability of capital adequacy requirements on economic efficiency measures using OLS model, is present in existing literature; see, for example, Barth et al. (2004); Pasiouras et al. (2009); Barth et al. (2013); and Sakouvogui and Shaik (2020). This critical analysis has been omitted in empirical studies, which often focus exclusively on hypotheses testing using the estimation sample, i.e. the evaluation of capital adequacy requirements on economic efficiency measures of banks (Barth et al. 2004; Barth et al. 2013; and Sakouvogui and Shaik, 2020). Determining the out-of-sample predictability of capital adequacy requirements on economic efficiency measures of banks is important due to three reasons: 1) The prediction of economic efficiency measures sheds light on how and why it impacts capital adequacy requirements; 2) The prediction of economic efficiency measures determines how well outturn economic efficiency measures compare with the original economic efficiency measures; and 3) Having a prediction of economic efficiency measures allows for an untangle view of bank's progress that is useful for management as it gains a high degree of transparency in the evaluation of future events.

With our interest lying in the out-of-sample prediction, it is thus important to guarantee that a significant conditionality of forecast performance of capital adequacy requirements on economic efficiency measures is not due to omitted variable bias. Fortunately, recent papers by Barth et al. (2004); Pasiouras et al. (2009); Barth et al. (2013); and Sakouvogui and Shaik (2020) have concluded in addition to capital adequacy requirements, Basel Accord III, bank's size, Dodd Frank Act, and annual state gross domestic product, are determining factors that are correlated with economic efficiency measures and have the additional advantage of usually exhibiting considerable association with the banking cycle.

This paper contributes to the debate on the effect of capital adequacy requirements on banks' economic efficiency measures in four aspects. First, economic efficiency measures of banks are estimated while accounting for the temporal (yearly) variation. Precisely, this paper focuses on U.S Commercial and Domestic banks that accept deposits and provide services, such as, loans, and certificates of deposits savings to both individual customers and small to midsized businesses. Furthermore, the temporal variation accounts for the heterogeneity's effect presents in the banking sector, and thus, could help banks and policy-makers make sound decisions.

Second, this paper employs tools from machine learning technique in addition to the benchmark, OLS model. Specifically, this paper uses Support Vector Regression (SVR) model with Linear, Polynomial, and Radial Basic Function (RBF) kernels and OLS model to investigate the out-of-sample predictability of capital adequacy requirements on banks' economic efficiency measures. According to Anderson and Audzeyeva (2019), "SVR is a data-driven, non-parametric model, that (1) unlike linear models, it does not require strong a-priori assumptions about the relationship between economic efficiency measures and exogenous variables, and (2) it is able to allay the issue of over-fitting inherent in the standard multivariate linear regression techniques."

Third, this paper compares the performance of OLS and SVR models by: a) applying Diebold-Mariano Test for forecast evaluations; b) estimating Mean Absolute Deviation (MAD) and Root Mean Square Error (RMSE); and c) using 
Model Confidence Set (MCS) methodology of Hansen et al. (2011) ${ }^{2}$

Our last contribution is empirical in nature. One prominent feature of this paper is the emphasis on a model's out-of-sample analysis using a sample period of December quarterly data of 10,380 U.S Commercial and Domestic banks spanning from 2008 through 2019. Hence, in using the long sample period, this paper minimizes the correlation between training and testing sets while allowing for a more robust estimate. To the best of our knowledge, this is the first paper that applies the SVR methodology in the context of economic efficiency measures with h-block cross-validation to account for serial correlation.

The remainder of this paper is structured as follows: Section 2 introduces DEA and SVR models. Section 3 presents the empirical data set including input and output variables. Section 4 discusses results and implications. Section 5 summarizes this paper and provides additional discussion.

\section{Theoretical Framework}

\subsection{Data Envelopment Analysis}

The theoretical cost theory assumes that the relationship between multiple producing output quantities, $y=\left(y_{1}, y_{2}, \ldots, y_{j}\right) \in \mathbb{R}_{+}^{J}$, inputs, $x=\left(x_{1}, x_{2}, \ldots, x_{o}\right) \in$ $\mathbb{R}_{+}^{O}$, and input prices, $w=\left(w_{1}, w_{2}, \ldots, w_{o}\right) \in \mathbb{R}_{+}^{O}$, is reflected by the concept of cost function. The cost function of an $i^{\text {th }}$ bank at time, $t$, can be expressed as:

$$
T C_{i t}=f\left(y_{i, t}, w_{i, t}\right), \quad i=1,2, \ldots, N ; \quad t=1,2, \ldots, T,
$$

where $T C_{i t}$ is the total cost of an $i^{\text {th }}$ bank at time, $t . y_{i t}$ is the vector of output quantities of an $i^{t h}$ bank at time, $t$. $w_{i t}$ is the vector of input prices of an $i^{t h}$ bank at time, $t$ associated with inputs, $x_{i t}$.

Economic efficiency measures from equation (1) can be estimated using the linear programming Data Envelopment Analysis (DEA) while accounting for temporal variation, $t$. In this paper, an input-oriented DEA model is used because banks have better control of inputs than outputs. Therefore, following Färe et al. (1985) and Sakouvogui (2020), the cost minimization DEA model of an $i^{\text {th }}$ bank can be defined as:

$$
\begin{aligned}
\varpi=\underset{\lambda, x_{o}}{\operatorname{minimize}} & w_{i}^{o} x^{* o} \\
\text { subject to } & \sum_{i=1}^{n} \lambda^{i} y^{j o} \geq y^{j}, j=1, \ldots, J, \\
& \sum_{i=1}^{n} \lambda^{i} x^{o i} \leq x^{* o}, \text { for } \forall o, \\
& \lambda^{i}>0, \text { for } \forall \lambda^{i},
\end{aligned}
$$

where $i=1, \ldots, n$ is the number of banks. $o=1, \ldots, O$ is the number of inputs. $j=1, \ldots, J$ measures the number of output quantities. $x_{o}^{*}$ is the cost

\footnotetext{
${ }^{2}$ In the case where there are multiple observations from one bank, care must be taken during model evaluation so that the same unique identifier does not appear in both the training and testing sets, because these are correlated and will lead to inflation of classifier's accuracy.
} 
minimizing vector of input quantities for the evaluated bank, given the vector of input prices, $w_{o}$, and output quantities, $y_{j}$.

Economic efficiency measures may differ depending on the scale assumptions that underpin the DEA model (equation 2). In the literature, two scale assumptions are generally employed, constant returns-to-scale (outputs change in the same proportion as inputs are changed) and variable returns-to-scale (production technology may exhibit increasing or decreasing returns-to-scale). Thus, if the variable returns-to-scale's convexity condition for the weight, $\lambda^{i}$, is included in the constraint of equation 2, then $\sum_{j=1}^{n} \lambda^{i}=1$. However, without the convexity constraint, $\sum_{j=1}^{n} \lambda^{i}=1$, equation 2 represents the constant returns-to-scale. Furthermore, to avoid bias of scale due to the economic efficiency measures, the scale efficiency measures, computed as the ratio of economic efficiency measures under constant returns-to-scale over pure technology estimated under variable returns-to-scale, are estimated.

After the estimation of economic efficiency measures in equation 2, this paper evaluates the out-of-sample predictability of capital adequacy requirements on economic efficiency measures of banks. To derive the magnitude of prediction for different factors influencing the economic efficiency measures, a simple SVR model of Cortes and Vapnik (1995) with Linear, Polynomial, and RBF kernel functions is used. We review the primal formulation, quadratic programming optimization and kernel functions of SVR model in Section 2.2.

\subsection{Support Vector Regression}

In a training set, $Z=\left(x_{1}, \varpi_{1}\right) \ldots . .,\left(x_{n}, \varpi_{n}\right)$, with independent variables, $x_{i} \in \mathbb{R}^{n}$, and dependent variable, economic efficiency measures, $\varpi_{i} \in \mathbb{R}_{+}^{n}$, the objective of SVR model is to find a function to predict the economic efficiency measures (target variable), $\varpi$. To fulfill this objective, SVR model considers a linear estimation function of predictive models for q-step-ahead forecasts of space $n$ at time, $t$, represented by:

$$
\begin{aligned}
\varpi_{t+q} & =f\left(x_{t}\right)+b_{t} \\
& =w_{1} \phi_{1}\left(x_{1}\right)+w_{2} \phi_{2}\left(x_{2}\right)+\ldots .+w_{n} \phi_{n^{\prime}}\left(x_{t}\right)+b_{t} \\
& =w^{T} \Phi\left(x_{t}\right)+b_{t},
\end{aligned}
$$

where $\phi(i): \mathbb{R}^{n} \rightarrow \mathbb{R}_{+}^{n}$ and weight, $w$, and constant, $b_{t}$, are the parameters learned from the training set, $Z$. $\Phi$ is a kernel function that maps the vector of independent vector, $x$, into a higher dimensional space.

SVR implements structural risk minimization with the purpose of constructing models with reliable out-of-sample performance (Vapnik, 1995). Instead of using the empirical risk minimization of an OLS's maximum likelihood estimation, which minimizes the error on observed data, SVR model seeks to minimize an upper bound on the generalization error (Anderson and Audzeyeva, 2019). This is done by mapping nonlinear independent variables, $x$, through kernel function, $\Phi$, into a higher dimensional feature space by finding the optimum weight, $w$, of the empirical risk minimization under $\varepsilon$-insensitive loss function, $\sum_{i=1}^{n} \max \left(\left|\varpi_{i}-w^{T} \Phi(x)-b\right|-\varepsilon, 0\right)$. Furthermore, for predicted values outside of the $\varepsilon$-tube, Cortes and Vapnik (1995) introduced the slack variables, $\xi$ and 
$\xi^{\prime}$, that allow for model complexity, and defined as:

$$
\begin{array}{cr}
\underset{w, b, \xi, \xi^{\prime}}{\operatorname{minimize}} & \frac{1}{2} w^{T} w+C \sum_{i=1}^{n}\left(\xi_{i}+\xi_{i}^{\prime}\right) \\
\text { subject to } & \left(\varpi_{i+q}-w^{T} \Phi\left(x_{i}\right)-b\right) \leq \varepsilon+\xi_{i} ; i=1, \ldots, n, \\
-\left(\varpi_{i+q}-w^{T} \Phi\left(x_{i}\right)-b\right) \leq \varepsilon+\xi_{i}^{\prime} ; i=1, \ldots, n,
\end{array}
$$

where $\frac{1}{2} w^{T} w$ accounts for the model complexity and $C$ is the cost or regulatization parameter that measures the trade-off between the model complexity, $\frac{1}{2} w^{T} w$, and the bandwidth, $\varepsilon$. The two positive slack variables, $\xi$ and $\xi^{\prime}$, represent the distance from actual values to the corresponding boundary values of $\varepsilon$-tube.

The prediction of the parameterized function can violate the constraint, but at a cost proportional to $C$. With this so called "double-hinged" loss function, the loss will be zero when $\left|\varpi_{i}-w^{T} \Phi(x)\right|<\varepsilon$ and increase linearly at the rate $\mathrm{C}$ for points where the predicted value falls outside the $\varepsilon$-insentive region. Therefore, SVR model accounts for: 1) Minimizing the training error ${ }^{3}$ and 2) Providing robustness against parameter-driven model over-fitting through the judicious choice of the regularization and bandwidth parameters (Anderson and Audzeyeva, 2019). Hence, using Lagrange multipliers, the quadratic dual of SVR model can restate the optimization problem as:

$$
\begin{aligned}
\underset{\alpha_{i}, \alpha_{i}^{\prime}}{\operatorname{minimize}} & \frac{1}{2} w^{T} w+C \sum_{i=1}^{n}\left(\xi_{i}+\xi_{i}^{\prime}\right)+\sum_{i=1}^{n} \varpi_{i}\left(\alpha_{i}-\alpha_{i}^{\prime}\right) \\
& -\varepsilon \sum_{i=1}^{n}\left(\alpha_{i}+\alpha_{i}^{\prime}\right)-\frac{1}{2} \sum_{i=1}^{n} \varpi_{i}\left(\alpha_{i}-\alpha_{i}^{\prime}\right)\left(\alpha_{j}-\alpha_{j}^{\prime}\right) \Phi\left(x_{i}\right)^{T} \Phi\left(x_{j}\right) \\
& \text { subject to } \\
& \sum_{i=1}^{n} \varpi_{i}\left(\alpha_{i}-\alpha_{i}^{\prime}\right)=0 ; i=1, \ldots, n \text { and } 0<\alpha_{i} \leq C .
\end{aligned}
$$

where the Lagrange multipliers, $\alpha_{i}$ and $\alpha_{i}^{\prime}$, are forces pushing and pulling the regression estimate towards the dependent variable, $\varpi_{i}$. Here the bandwidth parameter, $\varepsilon$, determines an $\varepsilon$-insensitive region for characterizing empirical risk, and the regularization parameter, $C$.

As for the nonlinear cases, SVR model can be made nonlinear by simply mapping the original problem into a high dimension space, in which dot product manipulation can be substituted by a kernel function, $\Phi$. Table 1 summarizes the kernel functions, Linear, Polynomial, and RBF, used in this paper with their associated parameters ${ }^{4}$ In Section 2.3, we show how to accommodate the cross-validation technique to deal with auto-correlation of economic efficiency measures.

\footnotetext{
${ }^{3}$ The minimization of training error is accomplished by minimizing $\xi$ and $\xi^{\prime}$.

${ }^{4}$ Given a kernel function and a set of tuning parameters, SVR model will produce a single forecasting model. However, changing tuning parameters would typically produce a different forecasting model.
} 
Table 1: Summary of kernel functions

\begin{tabular}{|l|l|l|}
\hline Name & Kernel functions, $k\left(x, x_{i}\right)$ & Specific parameters \\
\hline Linear & $k\left(x, x_{i}\right)=x_{i}^{T} x$ & \\
\hline Polynomial & $k\left(x, x_{i}\right)=\left(a+\gamma\left(x_{i}^{T} x\right)\right)^{d}$ & $\gamma, d$ and $a$ \\
\hline RBF & $k\left(x, x_{i}\right)=\exp \left(-\frac{1}{\phi^{2}\left\|x-x_{i}\right\|^{2}}\right)$ & $\phi$ \\
\hline
\end{tabular}

Each kernel function requires a choice of the cost parameter, $\mathrm{C}$, and the bandwidth parameter, $\varepsilon$. $\phi$ controls the radius of influence of individual observations. $d$ determines the degree of the linearity response. $a$ is the location of the point where the kernel function value is zero. $\gamma$ moderates the sensitivity to the nonlinear interaction term.

\subsection{Cross-Validation Technique}

This section outlines the procedure used for the selection of tuning parameter's candidates. SVR model's accuracy depends on the hyper-parameters: $C$ and $\varepsilon$, along with any kernel-specific parameters in Table 1. A most relevant question that we face in the selection of hyper-parameters is: How do we select the optimal hyper-parameters to avoid over-fitting and under-fitting in the estimation of SVR model? A solution to this problem of identification for the hyper-parameters is cross-validation.

Cross-validation is a technique that tests several combinations of hyperparameters to identify the optimal values. This method works best on the training set. However, if we train SVR model on the entire training set then over-fitting is inevitable. Thus, to guard against over-fitting, there is a dire need to extract a hold-out set from the training set. Furthermore, in order to conduct useful and statistically valid assessment with cross-validation, care must be taken due to the correlation present between a single variable. Fortunately, according to Sakouvogui and Nganje (2019) and Anderson and Audzeyeva (2019), there are many straightforward techniques for conducting cross-validation with auto-correlation, see for example, Burman et al. (1994), Hart and Yi (1998), Racine (2000), Hart and Lee (2005), and Carmack et al. (2009).

In this paper, the h-block cross-validation of Burman et al. (1994), a generalization of the well-known leave-one-out cross-validation approach, was conducted by withholding blocks of data when estimating kernel parameters of SVR model. Following Burman et al. (1994), assume that $Z$ is a set of jointly dependent stationary observations and $z_{i}$ the $i^{\text {th }}$ row (observation) of $Z$, then the covariance between $z_{i}$ and $z_{i+j}$ depends only on $j$ and approaches 0 as $|j-i| \rightarrow$ $\infty$ (Figure 1) ${ }^{5}$ To apply the h-block cross-validation, for each observation, $i$, we remove $h$ observations on either side of $z_{i}$, and thus, leading to a remaining local training set of size, $n_{c}=n-2 h-1{ }^{6}$ Hence, SVR model is trained on the

\footnotetext{
${ }^{5}$ Burman et al. (1994) have shown that the technique can produce statistically consistent results for model and variable selection in the presence of auto-correlation. The observations in Figure 1 come from the original training set. Thus, the cross-validation only uses data from this set.

${ }^{6} \mathrm{~h}$ limits the impact of auto-correlation, maintaining a "near" independence between training and testing sets by h-blocking. When $h=0$, a "leave-one-out" cross-validation is used.
} 
local training set, $n_{c}$. The h-block cross-validation function is given by:

$$
C V_{h}=\frac{1}{n} \sum_{i=1}^{n}\left(\varpi_{i}-\hat{\varpi}_{i(-i: h)}\right)^{2}
$$

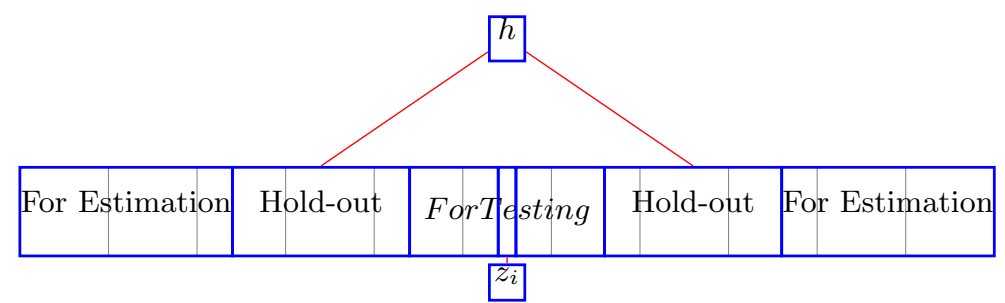

Figure 1: H-block cross-validation

The training set encompasses the estimation and hold-out sets. Henceforth, the optimal parameters of SVR model and cross-validation are found using the training set. Therefore, a set of experiments for SVR model with Linear, Polynomial, and RBF kernel functions, are considered in Table 2. Thus, in Table 2, an exponentially growing sequences of hyper-paramters was used to identify the optimal hyper-parameters.

Table 2: Tuning parameter search ranges

\begin{tabular}{|l|l|}
\hline Kernels & Specific parameters \\
\hline Linear & $\mathrm{C} \in(1,100) ; \varepsilon \in(0.001,1)$ \\
\hline Polynomial & $\mathrm{C} \in(1,100) ; \varepsilon \in(0.001,1) ; \gamma \in(1,20) ; a \in(1,5) ; d \in(1,10)$ \\
\hline $\mathrm{RBF}$ & $\mathrm{C} \in(1,100) ; \varepsilon \in(0.001,1) ; \phi \in(1,20)$ \\
\hline
\end{tabular}

The optimal parameters are found using the training set.

\section{Data and Construction of Variables}

In this paper, following Sakouvogui and Shaik (2020), a total of over 10,380 December quarterly observations of U.S Commercial and Domestic banks was selected from 2008 to 2019. The data is from the Federal Financial Institutions Examination Council based on the Council Form 041 Report of Condition and Income of U.S. Commercial and Domestic banks that report to the Federal Reserve Board. In the selection of output quantities and input prices pertinent to the economic efficiency measures, we follow the intermediate approach of economic theory presented in Pessarossi and Weill (2015) and Sakouvogui and Shaik (2020) 7

Two output quantities, total loans $\left(y_{1}\right)$ and other earning assets $\left(y_{2}\right)$, are selected with three input prices, price of labor, $\left(w_{1}\right)$, calculated as the ratio of

\footnotetext{
${ }^{7} \mathrm{~A}$ full description of data and methodology underlying the construction appears in Sakouvogui and Shaik (2020). The intermediate approach, used in this paper, suggests that banks collect deposits to transform them into loans and capital. Furthermore, there are two additional approaches pertinent for the selection of input and output variables, Production of Sherman and Gold (1985) based on production theory, and Profitability of Drake et al. (2006) based on profit theory.
} 
personnel expenses to total assets, price of physical capital, $\left(w_{2}\right)$, calculated as the ratio of other operating expenses to premises and fixed assets, and price of borrowed funds, $\left(w_{3}\right)$, calculated as the ratio of interest expenses to total deposits $8^{8}$ The dependent variable, total cost $(T C)$, is the sum of interest expenses, personnel expenses, and other operating expenses. We additionally impose homogeneity conditions by normalizing respectively $T C, w_{1}$ and $w_{2}$ by $w_{3}$.

Furthermore, in the predictive analysis of economic efficiency measures, we employ exogeneous variables that have been previously analyzed. Accordingly, the potential exogenous factors affecting the economic efficiency measures include capital adequacy requirements (Sol), bank's size (size), state GDP (GDP), Basel Accord III (Basel3) and Dodd Frank Act (Dodd). Equation (3), rewritten into equation (8) to account for the construction of SVR model for 3-step-ahead forecasts of an $i^{\text {th }}$ bank at time, $t$, is:

$$
\varpi_{i t+3}=w^{T} \Phi\left(\text { Sol }_{i t}, \text { size }_{i t}, G D P_{i t}, \text { Basel3, Dodd }\right)+b_{t},
$$

where $\varpi_{i t}$ is the estimated economic efficiency measures of an $i^{\text {th }}$ bank at time, $t$ using equation (2) 9

Table 3 presents the summary statistics, mean, standard deviation, minimum, and maximum of bank-specific and economic variables of 10,380 December quarterly observations of U.S Commercial and Domestic banks ranging from 2008 to 2019. To reduce the effect of spurious outliers, variables are logathorised with Figures 2 and 3 presenting their evolutions across the years. Figures 2 and 3 further show that although the dynamics of year exhibit common trends across the input prices and output quantities, driven by various factors, the size of banks variations are, nevertheless, apparent. Such variations primarily reflect differences in specific banks.

\footnotetext{
${ }^{8}$ As presented in Sakouvogui and Shaik (2020), the variables are defined as follows. Total loans is the sum of loans secured by real estate, agricultural production, farmers, commercial real estate, construction, land development activities, individuals for household, family, other personal expenditures, credit cards and construction. Other earning assets consists of balances due from the bank, inter-bank loans, investments, and securities. Price of labor is the price associated with the sum of all wages paid to employees, as well as the price of employee benefits. Personnel expenses include salaries and employee benefits. Total asset is the sum of total loans and leases, total held-to-maturity securities, total available-for-sale securities, trading assets, total intangible assets, other real estate owned, all other assets minus Allowance for loan and lease losses. Price of physical capital is the price of maintaining building. Other operating expenses is the sum of goodwill impairment losses, amortization expenses and impairment losses for other intangible assets. Fixed assets are assets which are purchased for long-term use and unlikely to be quickly converted into cash. Price of borrowed funds is the price of associated with borrowing money. The total interest expense is the sum of the interest expense. Total deposit is the sum of all domestic deposits including demand, saving and fixed deposits minus noninterest bearing and interest bearing. Total equity is the total holding company or bank equity capital, including paid-up capital, share premiums and reserves.

${ }^{9}$ Capital adequacy requirements, defined as $\log \left(\frac{\text { Total equity }}{\text { Total assets }}\right)$, is the capacity of banks to face difficulties during the downturn. Bank's size, defined as the natural logarithm of total amount of assets, measures the total amount of assets owned by banks. Basel Accord III (basel3), banking regulation agreements proposed in 2010 and implemented from 1st of January of 2013 till 1st of January of 2019, is a dummy characterized by: 1 if year $=2013$ and 0 otherwise (https : //www.federalreserve.gov/supervisionreg/basel/USImplementation.htm\#Basel $I_{I} I_{T}$ ools). State GDP, defined the natural logarithm of GDP, measures the total market value of all the finished goods and services produced within a state (https : //www.bea.gov/).
} 
Table 3: Summary statistics of input and output variables

\begin{tabular}{|c|c|c|c|c|}
\hline Variable & Mean & Std.dev & Mini & Maxi \\
\hline & \multicolumn{4}{|c|}{ Input prices and Output quantities } \\
\hline Total cost & 14.699 & 1.854 & 10.496 & 23.467 \\
\hline Price of labor & 0.506 & 0.892 & -3.572 & 4.518 \\
\hline Price of physical capital & 0.759 & 1.766 & -7.358 & 12.544 \\
\hline Total loans & 7.572 & 2.174 & 0.08 & 19.153 \\
\hline \multirow[t]{2}{*}{ Other earning assets } & 10.119 & 1.893 & 5.756 & 18.774 \\
\hline & \multicolumn{4}{|c|}{ Predictive variables } \\
\hline Capital adequacy requirements & -2.277 & 0.28 & -5.029 & -0.537 \\
\hline Size & 13.701 & 1.775 & 10.176 & 22.027 \\
\hline State GDP & 12.674 & 0.978 & 10.145 & 14.973 \\
\hline
\end{tabular}

Mean: overall mean. std: standard deviation. Mini: minimum. Maxi: maximum. 

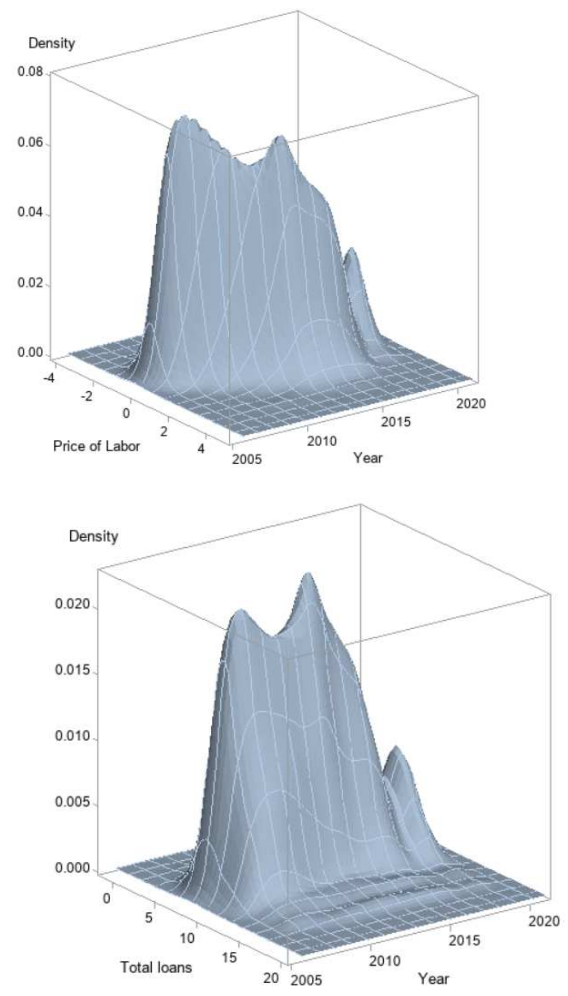

( $w_{1}$ and year)

$$
\left(y_{1}\right. \text { and year) }
$$
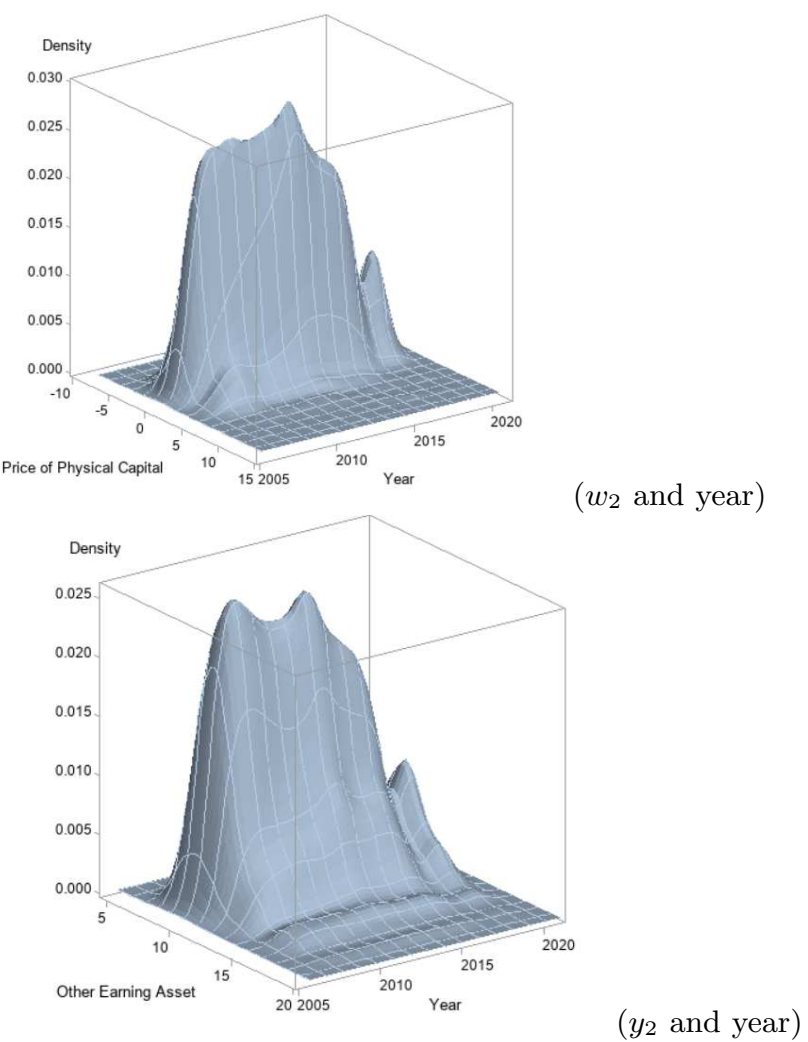

Figure 2: Distribution of input prices and output quantities across years. 

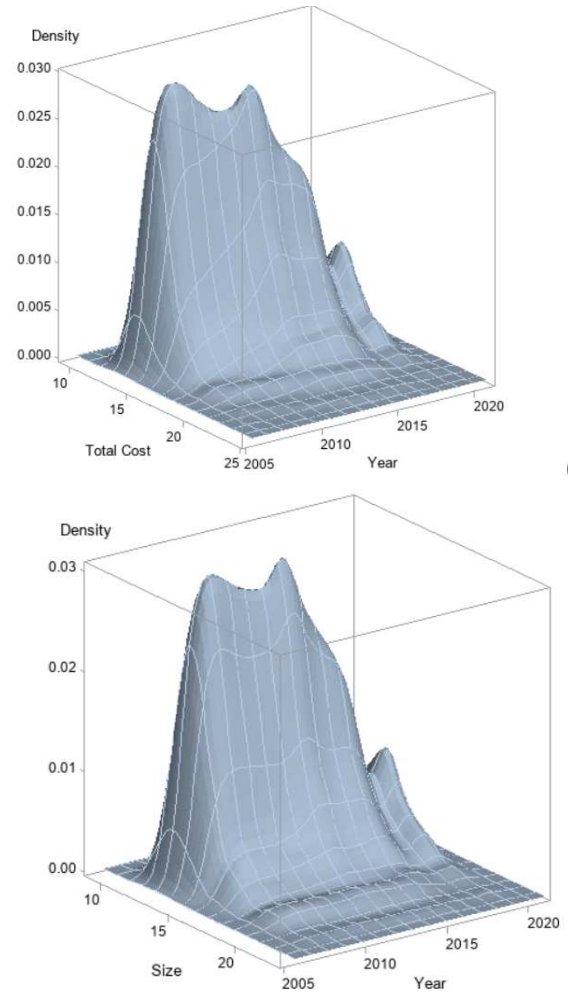

(TC and year)

Size and year)
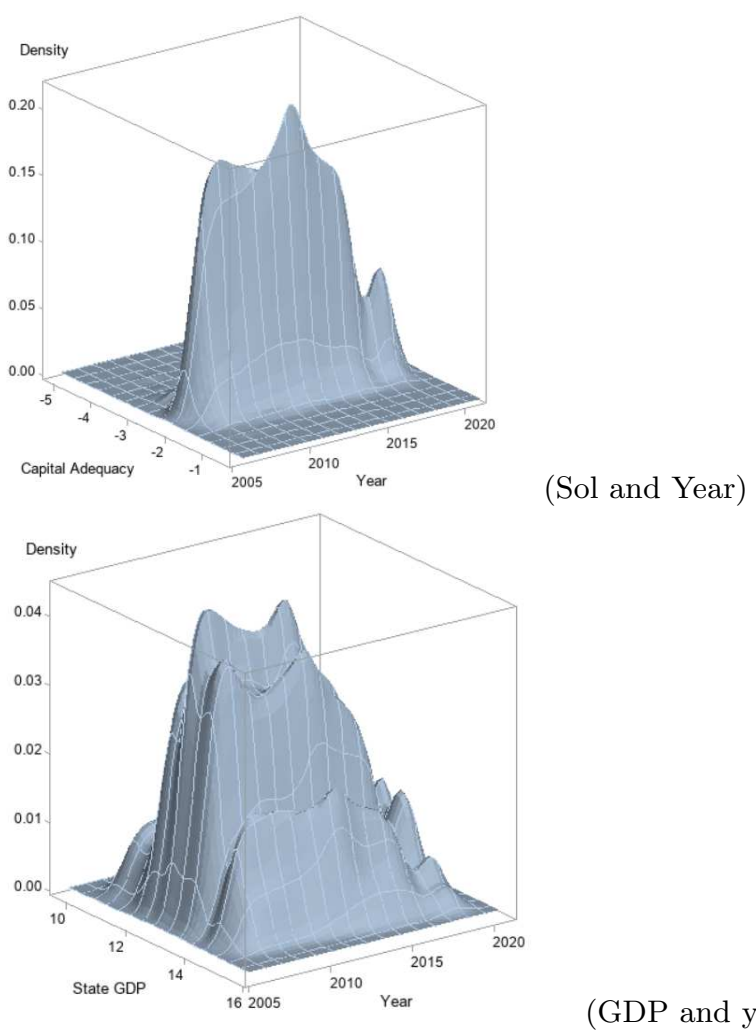

(GDP and year)

Figure 3: Distribution of log of total cost and exogeneous variables across years 


\subsection{Empirical Estimation Framework}

The empirical application of our paper is straightforward and entails a four-step process presented as follow:

1. The first step involves the estimation of economic efficiency measures using DEA model (equation 2) while accounting for temporal variation.

2. The second step deals with the partition of 10,380 December quarterly observations of U.S Commercial and Domestic banks into training and testing sets. For the out-of-sample predictability analysis, we follow the framework of Anderson and Audzeyeva (2019) and thus allocate for training set, the quarterly data from December 2008 through December 2015 (8,063 consecutive observations) available in the data sample period. The forecast accuracy of SVR and OLS models is determined using the remaining quarterly data, testing set, spanning from December 2016 through December 2019 (2,317 consecutive observations).

3. The third step involves the estimation of optimal hyper-parameters for SVR model with Linear, Polynomial, and RBF kernel functions. The guidelines of Burman et al. (1994) support $\mathrm{h}=76$, for our training dataset of 7,912 observations. For estimation, the tuning parameters of SVR model with Linear, Polynomial, and RBF kernel functions, are trained using the quarterly observations from December 2008 through December 2013 (estimation set) and to find optimal parameters, the remaining observations of the training set, spanning from December 2014 through December 2015, is used as the hold-out set.

4. Finally, in the last step, we assess the out-of-sample forecasting accuracy while permitting for the selection of best performing model. The forecast accuracy of SVR and OLS models are determined using the testing set, composed of quarterly observations spanning from December 2016 through December 2019. That is, based on the estimated economic efficiency, the forecasting accuracy of SVR model is estimated and compared to the forecasting accuracy of OLS model.

The implementation of SVR and OLS models and related functions used in this paper are scripted using $\mathrm{R}$ statistical language.

\section{Empirical Application and Results}

\subsection{Economic Efficiency Measures}

In this paper, using equation (2), economic efficiency measures under CRS, VRS, and scale assumptions were estimated while accounting for the yearly variability and thus, for technological change.

Table 4 presents the annual summary statistics of economic efficiency measures of DEA model under CRS, VRS, and scale assumptions. In Table 4, three interesting results emerge. First, the minimum and maximum economic efficiency measures are high. This is expected due to the lack of random noise presents in DEA model and the suggestion that banks are generally efficient. 
Second, the mean of economic efficiency measures fluctuates slightly throughout the years. That is, using DEA model (equation 2), the yearly average of economic efficiency measures ranges between 0.594 to 1.000 under CRS assumption, between 0.657 to 1.000 under VRS assumption and between 0.631 to 1.000 under the scale assumption. Finally, in column 3 of Table 4, for large standard deviations, there exists a large variation between the minimum economic efficiency measures in that year and its average. Precisely, in DEA model under CRS, VRS, and scale assumptions, the majority of banks have economic efficiency measures ranging from 0.718 to 0.812 , from 0.797 to 0.885 , and from 0.847 to 0.975 , respectively. Furthermore, a comparison of the ratio suggests that VRS technology overestimates on average and this is suggested by the economic efficiency measures of the DEA model under scale assumption. Figures 4,5 and 6 display respectively the distributions of the estimated economic efficiency measures under CRS, VRS, and scale assumptions. From Figures 4 and 5, the histograms of economic efficiency measures are skewed to the right whereas in Figure 6, they are skewed to the left.

Table 4: Summary of economic efficiency measures

\begin{tabular}{|c|c|c|c|c|c|c|c|c|c|}
\hline Year & Mean & Std.dev & Minimum & Maximum & Year & Mean & Std.dev & Minimum & Maximum \\
\hline & \multicolumn{9}{|c|}{ CRS assumption } \\
\hline Pooled & 0.765 & 0.062 & 0.594 & 1.000 & 2014 & 0.770 & 0.064 & 0.626 & 1.000 \\
\hline 2008 & 0.784 & 0.066 & 617 & 1.000 & 2015 & 0.767 & 0.060 & 0.625 & 1.000 \\
\hline 2009 & 0.762 & 0.057 & .594 & 1.000 & 2016 & 0.762 & 0.058 & 0.627 & 0.992 \\
\hline 2010 & 0.760 & 0.060 & 0.610 & 1.000 & 2017 & 0.758 & 0.058 & 0.627 & 0.962 \\
\hline 2011 & 0.761 & 0.063 & 0.606 & 0.987 & 2018 & 0.779 & 0.076 & 0.653 & 0.980 \\
\hline 2012 & 0.763 & 0.061 & 0.617 & 0.981 & 2019 & 0.754 & 0.058 & 0.620 & 1.000 \\
\hline \multirow[t]{2}{*}{2013} & 0.767 & 0.063 & 0.625 & 1.000 & & & & & \\
\hline & \multicolumn{9}{|c|}{ VRS assumption } \\
\hline Pooled & 0.841 & 0.052 & 0.657 & 1.000 & 2014 & 0.849 & 0.053 & 0.657 & 1.000 \\
\hline 2008 & 0.848 & 0.054 & 0.708 & 1.000 & 2015 & 0.852 & 0.052 & 0.729 & 1.000 \\
\hline 2009 & 0.826 & 0.047 & 0.687 & 1.000 & 2016 & 0.852 & 0.051 & 0.727 & 1.000 \\
\hline 2010 & 0.823 & 0.047 & 0.682 & 1.000 & 2017 & 0.851 & 0.047 & 0.741 & 1.000 \\
\hline 2011 & 0.828 & 0.051 & 0.675 & 1.000 & 2018 & 0.873 & 0.049 & 0.755 & 1.000 \\
\hline 2012 & 0.835 & 0.051 & 0.710 & 1.000 & 2019 & 0.852 & 0.050 & 0.717 & 1.000 \\
\hline \multirow[t]{2}{*}{2013} & 0.843 & 0.052 & 0.711 & 1.000 & & & & & \\
\hline & \multicolumn{9}{|c|}{ Scale assumption } \\
\hline Pooled & 0.911 & 0.070 & 0.631 & 1.000 & 2014 & 0.908 & 0.070 & 0.641 & 1.000 \\
\hline 2008 & 0.926 & 0.064 & 0.631 & 1.000 & 2015 & 0.902 & 0.071 & 0.643 & 1.000 \\
\hline 2009 & 0.924 & 0.065 & 0.642 & 1.000 & 2016 & 0.896 & 0.072 & 0.646 & 1.000 \\
\hline 2010 & 0.925 & 0.065 & 0.648 & 1.000 & 2017 & 0.893 & 0.071 & 0.640 & 1.000 \\
\hline 2011 & 0.920 & 0.067 & 0.647 & 1.000 & 2018 & 0.893 & 0.073 & 0.677 & 1.000 \\
\hline 2012 & 0.915 & 0.068 & 0.646 & 1.000 & 2019 & 0.888 & 0.074 & 0.633 & 1.000 \\
\hline 2013 & 0.911 & 0.069 & 0.645 & 1.000 & & & & & \\
\hline
\end{tabular}

Year: time of economic efficiency measures. Pooled: overall mean and standard deviation of economic efficiency measures. Minimum: minimum economic efficiency measures over time. Maximum: maximum economic efficiency measures over time. 


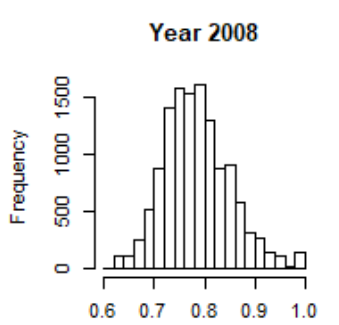

Efficiency

Year 2012

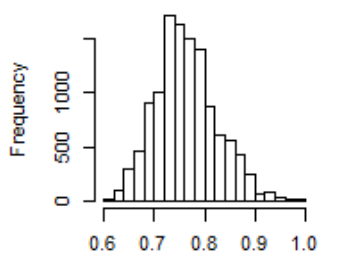

Efficiency

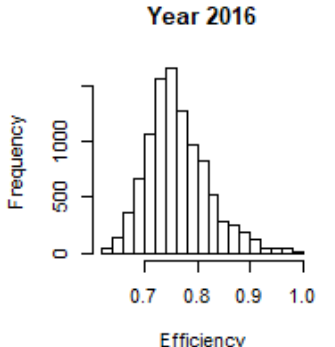

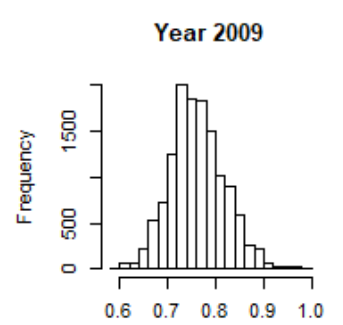

Efficiency

Year 2013

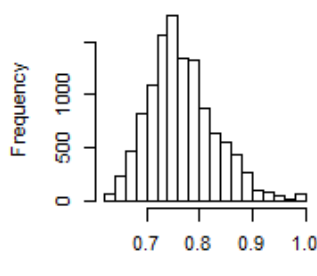

Efficiency

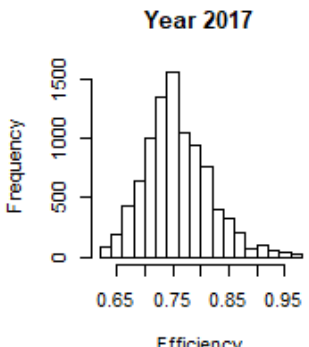

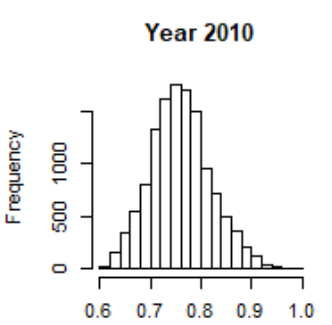

Efficiency

Year 2014

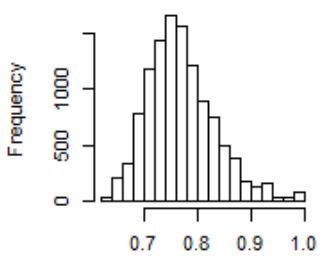

Efficiency

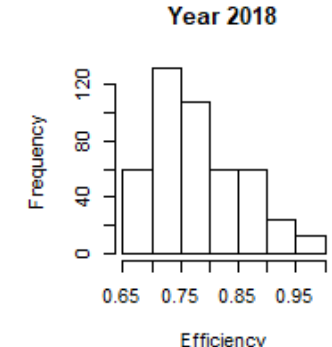

Year 2011

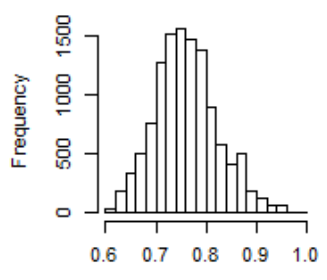

Efficiency

Year 2015
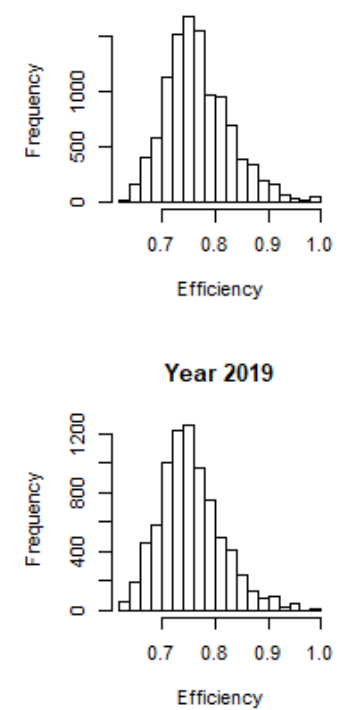

Figure 4: Economic efficiency measures under CRS assumption 

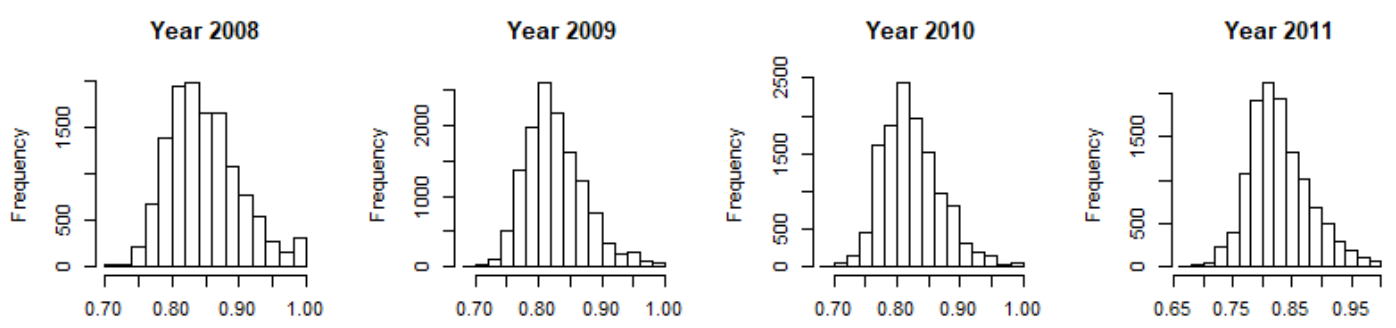

Year 2012

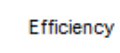

Efficiency

Efficiency

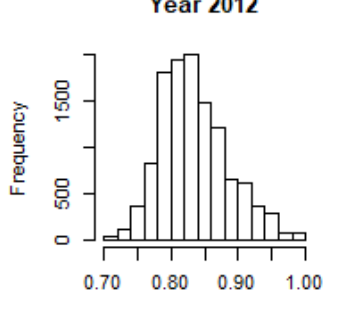

Year 2013
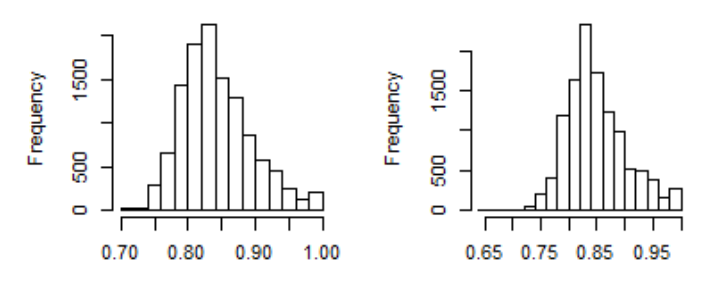

Year 2015

Efficiency

Year 2017

Efficiency

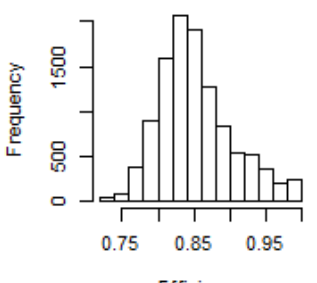

Year 2016
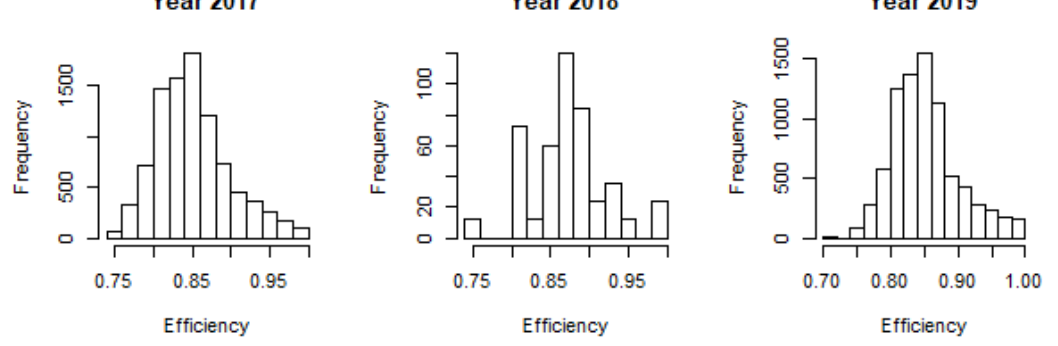

Figure 5: Economic efficiency measures under VRS assumption 


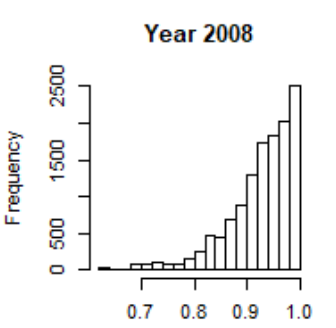

Efficiency

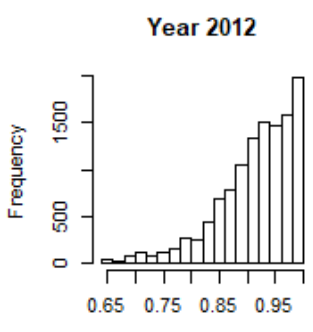

Efficiency

Year 2016

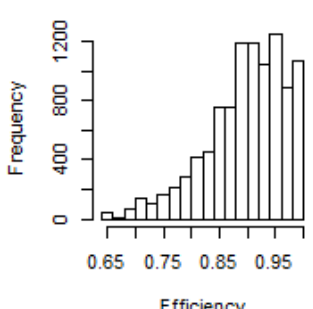

Year 2009

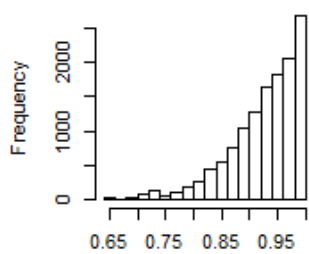

Efficiency

Year 2013

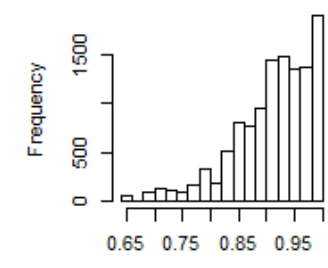

Efficiency

Year 2017

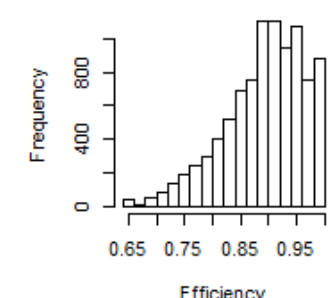

Year 2010

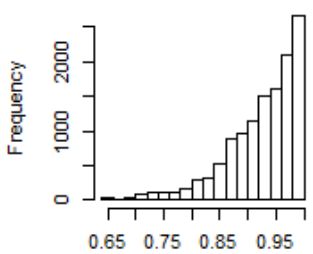

Efficiency

Year 2014

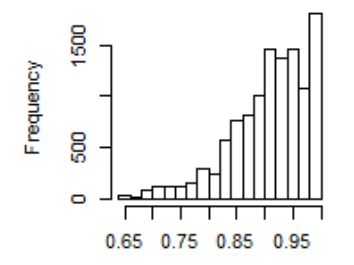

Efficiency

Year 2018

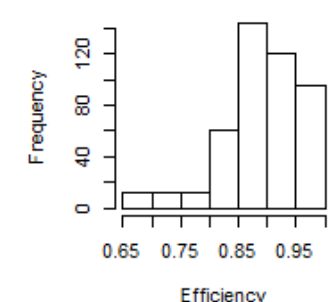

Year 2011

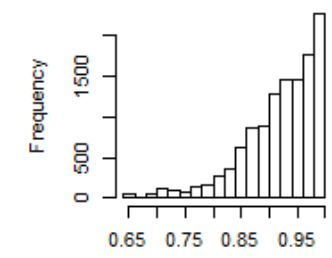

Efficiency

Year 2015

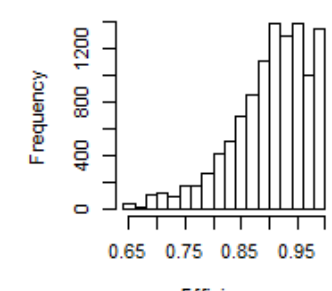

Year 2019

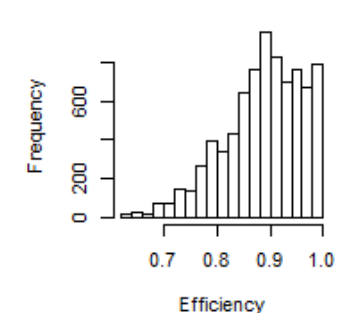

Figure 6: Economic efficiency measures under scale assumption 


\subsection{Stationarity of Economic Efficiency Measures}

The analysis of stationarity is essential for out-of-sample analysis of SVR and OLS models. This is primarily important because a non-stationary series of economic efficiency measures can lead to spurious regression results with bias asymptotic properties. Therefore, the Augmented Dickey-Fuller test of Dickey and Fuller (1979) is used to test for stationarity of economic efficiency measures. Thus, for a given time series observations of economic efficiency measures, $\varpi_{1} \ldots \varpi_{n}$, the presence of a unit root in the data generating mechanism is obtained by fitting the regression equation:

$$
\varpi_{t}=\rho \varpi_{t-1}+\sum_{j=1}^{5} \rho_{j} \Delta \varpi_{t-j}+\epsilon_{t},
$$

where $\Delta \varpi_{t}=\varpi_{t}-\varpi_{t-1}, \mathrm{p}=1, \ldots, 5$ predictors, $\rho$ is the OLS estimate, $\epsilon_{t}$ is independent and identically distributed with mean, 0 , and variance, $\sigma^{2}$. Under, the null-hypothesis, $H_{o}: \rho=1$, and with $\hat{\rho}_{n}$ been the estimator of $\rho$, Dickey and Fuller (1979) proposed the studentized statistic, $t_{n}=\frac{\hat{\rho}_{n}-1}{S \hat{t} d\left(\hat{p}_{n}\right)}$, where $\hat{S t d}\left(\hat{p}_{n}\right)$ is the standard deviation of the estimator $\hat{\rho}_{n}$. The results of Augmented DickeyFuller test suggest that there is a significant statistical evidence to conclude that the economic efficiency measures are stationary at the $5 \%$ significance level. Additionally, Table 5 presents the results of Spearman's rank correlation between the dependent variable, economic efficiency measures, and exogeneous variables, capital adequacy requirements, bank's size, and state GDP. From Table 5, a significant Spearman's rank correlation is found among economic efficiency measures, and exogeneous variables.

Table 5: Correlation analysis between the efficiency measures and exogenous variables

\begin{tabular}{|c|c|c|c|c|}
\hline Variables & Economic efficiency measures & Sol & Size & GDP \\
\hline & \multicolumn{4}{|c|}{ Pearson's correlation coefficient } \\
\hline Economic efficiency measures & 1.000 & -0.044 & -0.971 & -0.196 \\
\hline Sol & & 1.000 & 0.040 & 0.050 \\
\hline Size & & & 1.000 & 0.183 \\
\hline GDP & & & & 1.000 \\
\hline
\end{tabular}

Strong correlation: -1.0 to -0.5 or 1.0 to 0.5 . Moderate correlation: -0.5 to -0.3 or 0.3 to 0.5 . Weak correlation: -0.3 to -0.1 or 0.1 to 0.3 . Very weak correlation: -0.1 to 0.1 . Economic efficiency measures: Efficiency measures estimated with the DEA's model under scale assumption. Sol: Capital adequacy requirements. Size: Bank's size. GDP: State Gross Domestic Products.

\subsection{Optimization of Tuning Parameters}

While the optimization technique of SVR model is theoretically sound and relatively straight forward to implement, literature has emphasized that its performance is highly sensitive to the selected kernels and tuning parameters (Song and Zen, 2008; Sakouvogui, 2015; and Anderson and Audzeyeva, 2019). Therefore, studies tend to resort to applying a grid-search optimization technique, in conjunction with a metric characterizing the goodness-of-fit, typically based 
on MAD and RMSE, see, for example, Min and Lee (2005), and Gunduz and Uhrig-Homburg (2011), Nayak et al. (2015), Patel et al. (2015), Manahov et al. (2014), Choudhury et al. (2014), Sakouvogui and Njange (2019), and Anderson and Audzeyeva (2019) 10

However, in the presence of serially correlated data series, the standard SVR forecasting methodology may be unsuitable due to the failure of the standard cross-validation schemes to interpret the serial correlation as a high frequency relationship with small variance, leading to spurious parameter choices (Brabanter et al. 2011). Therefore, in adopting the h-block cross-validation to deal with the serial correlation, we employ only the training set at this stage. To guard against overfitting, we extract an estimation set and a hold-out set from the training set. SVR model with Linear, Polynomial and RBF kernel functions is trained using the estimation set, composed of 5,280 consecutive observations. To find the optimal hyper-parameters, SVR model with Linear, Polynomial and $\mathrm{RBF}$ kernel functions is tested using the hold-out set, composed of the remaining 2,632 last consecutive observations of the training set. Henceforth, the hyperparameter combination that gives the best model statistics, MAD and RMSE, for the hold-out set is considered as optimal.

Table 6 presents the results of MAD and RMSE for the selection of optimal hyper-parameters for SVR model with Linear, Polynomial, and RBF kernel functions. An appropriate value of the kernel's parameters produces the minimum MAD and RMSE and thus provide the best optimal values for possible forecasts.

Table 6: Optimization of SVR model using the training set

\begin{tabular}{|c|c|c|c|c|}
\hline & OLS & SVR-Linear & SVR-Polynomial & SVR-RBF \\
\hline & \multicolumn{4}{|c|}{ Performance Criteria } \\
\hline MAD & 0.01243 & 0.01231 & 0.01092 & 0.00990 \\
\hline \multirow{2}{*}{ RMSE } & 0.01685 & 0.01676 & 0.01589 & 0.01371 \\
\hline & \multicolumn{4}{|c|}{ Optimal hyper-parameter values } \\
\hline Cost & & 54 & 60 & 46 \\
\hline$\varepsilon$ & & 0.04 & 0.031 & 0.036 \\
\hline$a$ & & & 3 & \\
\hline$d$ & & & 3 & \\
\hline$\phi$ & & & 13 & 15 \\
\hline
\end{tabular}

SVR Kernels: Linear, Polynomial, and RBF. The lower the value of MAD and MSE, the better SVR is able to forecast values.

\subsection{Predictive Analysis}

After selecting the optimal hyper-parameters of SVR model in Table 6, our next step is to forecast based on the unseen testing set of quarterly data spanning from December 2016 through December 2019. Table 7 presents the results of prediction performance, MAD and RMSE, for OLS and SVR models.

\footnotetext{
${ }^{10} \mathrm{MAD}=\frac{1}{n} \sum_{i=1}^{n}\left|\varpi_{i}-\hat{\varpi}_{i}\right|$ and RMSE $=\sqrt{\frac{1}{n} \sum_{i=1}^{n}\left(\varpi_{i}-\hat{\varpi}_{i}\right)^{2}}$, where $n$ is the sample size of the hold-out set, $\varpi_{i}$ and $\hat{\varpi}_{i}$ are respectively the true and predicted economic efficiency measures of the hold-out set.
} 
In comparison of Table 6 , the application of SVR model with Linear, Polynomial and RBF kernel functions in Table 7 reveals that the performance criteria, MAD and RMSE, are smaller using the testing set. This behavior is not always expected, as SVR model is optimized using the training set in Table 6. Furthermore, to evaluate the performance accuracy of SVR and OLS models, the Diebold-Mariano test (1991 and 1995) of forecast errors is used. That is, by considering two forecasts, $\hat{\varpi}_{i t}$ and $\hat{\varpi}_{j t}$ of the time series $\varpi_{i t}$ with the associated forecast errors, $\hat{e}_{i t}$ and $\hat{e}_{j t}$, the Diebold-Mariano test is used to assess the expected loss associated with each of the forecasts based on the loss differential, $d_{t}=\hat{e}_{i t}-\hat{e}_{j t}$. Under the null-hypothesis of equal predictive accuracy, $E\left[d_{t}\right]=0$, the Diebold-Mariano test for time, $t=t_{1}, \ldots, \mathrm{T}$ for a total of $T_{0}$ forecasts is:

$$
S=\frac{\bar{d}}{\left(L \hat{R} V_{\bar{d} / T)^{1 / 2}}\right.}
$$

where $\bar{d}=\frac{\sum_{t=1}^{T} d_{t}}{T_{0}}$ and $L \hat{R} V_{\bar{d}}=\operatorname{cov}\left(d_{t}, d_{t-j}\right)$. Table 7 presents the results of the Diebold-Mariano test. At the horizon of three quarters ahead, DieboldMariano test statistically rejects the null-hypothesis of the forecast errors being the same. To further illustrate the capabilities of SVR model, Figure 7 presents a three-dimensional plot of the testing set spanning from December 2017 through December 2019 for actual and predicted economic efficiency measures.

Table 7: Out-of-sample analysis of economic efficiency measures

\begin{tabular}{rrrrr}
\hline & OLS & SVR-Linear & SVR-Polynomial & SVR-RBF \\
\hline & \multicolumn{4}{c}{ Performance Criteria } \\
\cline { 2 - 5 } MAD & 0.00378 & 0.00172 & 0.00155 & 0.00120 \\
RMSE & 0.04619 & 0.03057 & 0.02293 & 0.01621 \\
& \multicolumn{4}{c}{ Diebold-Mariano test } \\
\cline { 2 - 5 } SVR-Linear & $-2.15521^{*}$ & $-11.168^{* * *}$ & $-7.0048^{* * *}$ \\
SVR-Polynomial & $11.14^{* * *}$ & $-11.168^{* * *}$ & $10.747^{* * *}$ \\
SVR-RBF & $7.0362^{* * *}$ & $-7.0048^{* * *}$ & $10.747^{* * *}$ & \\
\hline
\end{tabular}

SVR-Linear: SVR model with Linear kernel function. SVR-Polynomial: SVR model with Polynomial kernel function. SVR-RBF: SVR model with RBF kernel function. The lower the value for MAD and RMSE, the better a model is able to forecast the economic efficiency measures. 


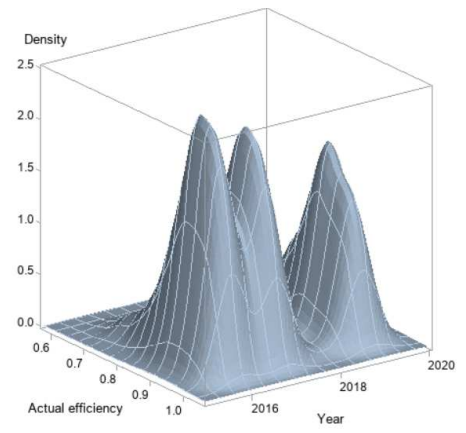

(Actual DEA)
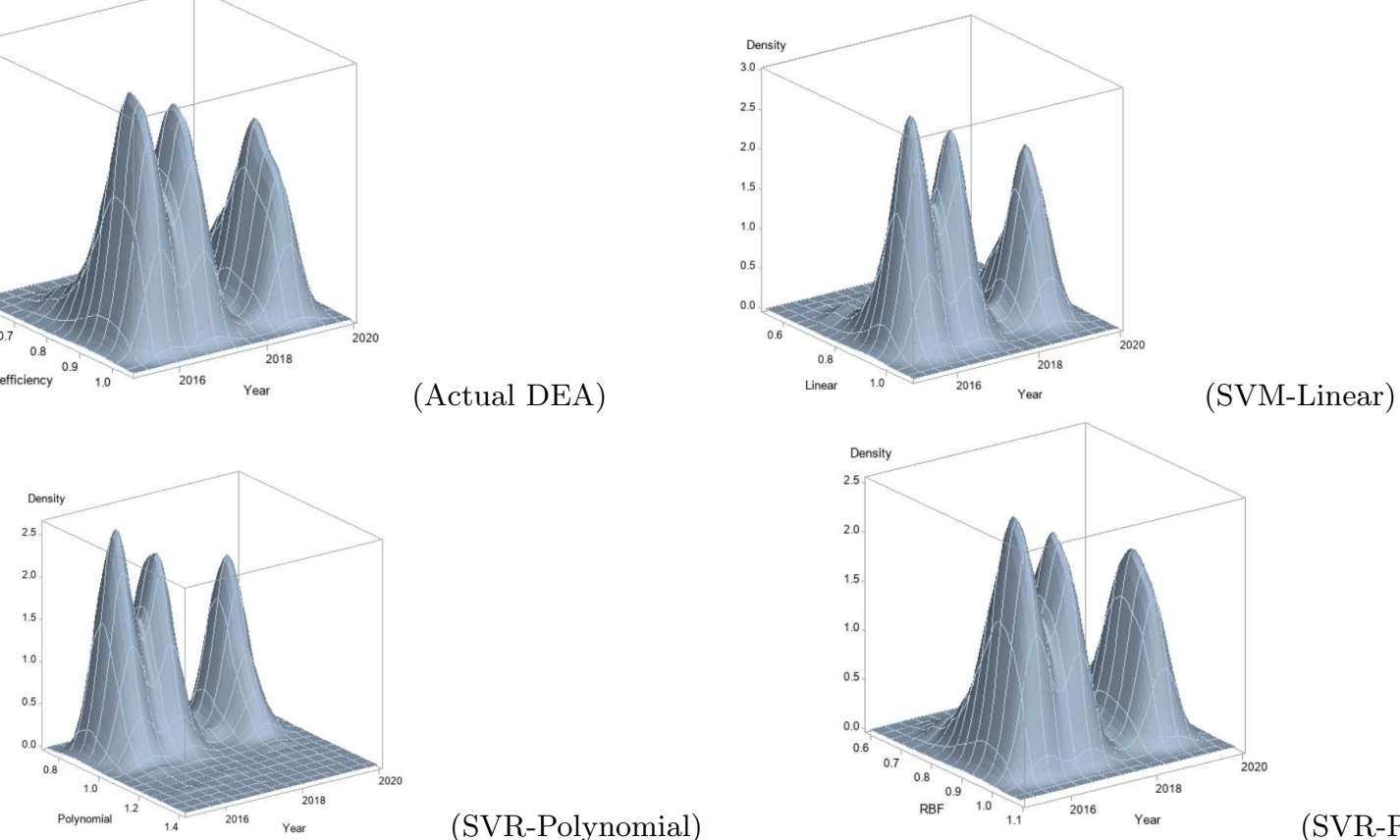

(SVR-Polynomial)

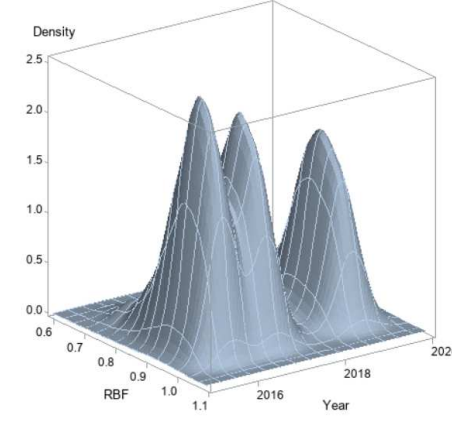

(SVR-RBF

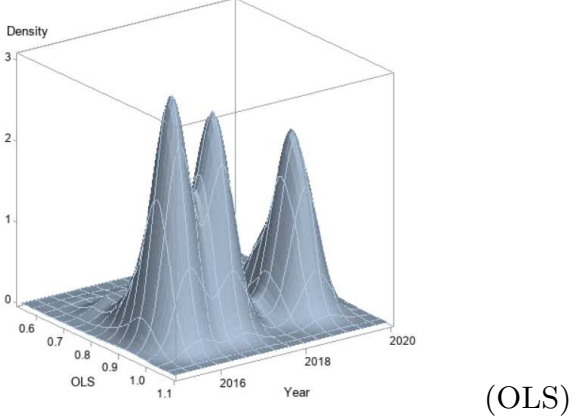

Figure 7: Prediction of economic efficiency measures 


\section{$5 \quad$ Model Selection}

Using the performance criteria of MAD and RMSE, Table 7 further shows that there is no persuasive evidence for singling out the best models among OLS, SVR with Linear kernel, SVR with Polynomial kernel, and SVR with RBF kernel, that may be most suited for modeling the economic efficiency measures. That is, MAD and RMSE values show that the forecast of economic efficiency measures deviates from the realized economic efficiency measures. Therefore, a most relevant question in analyzing the competing models that we face while guarding against data snooping is: Which model is the best?

Effectively, comparing several models, SVR with Linear kernel, SVR with Polynomial kernel, and SVR with RBF kernel, to a benchmark, OLS model, may result inspuriously in identifying a superior model just by chance. To account for this data snooping issue, we adopt the Model Confidence Set (MCS) proposed by Hansen et al. (2011) and based on the seminal papers of Hansen (2005) and White (2000) for selecting a subset of a group of models whose members likely have the best forecasting accuracy.

In the selection of the best model, MCS seeks to find a group of models that are equally likely to be superior. MCS has three important advantages over widely used alternative tests of Diebold and Mariano (1995), White (2000), Hansen (2005), Hansen, and Lunde (2010), and Harvey and Liu (2019). First, MCS provides a measure of uncertainty surrounding model selections. Second, MCS increases as the level of confidence increases. Third, unlike alternative tests of pair-wise model comparisons, MCS requires less information about the optimal forecasting model.

Let's the squared error loss function for the model $j^{\prime}$ prediction $\hat{\varpi}_{j^{\prime}, t}$ of $\varpi_{t}$ be given by $L_{j^{\prime}, t}=\mathrm{L}\left(\varpi_{t}, \hat{\varpi}_{j^{\prime}, t}\right)=\left(\hat{\varpi}_{j^{\prime}, t}-\varpi_{t}\right)^{2}$. Henceforth, the best model is the model whose forecasts produce the minimum expected loss. Hansen et al. (2011) defined the measure of relative model performance, $\nu_{j^{\prime} j^{\prime \prime}}$, finite and independent of $t$, as: $\nu_{j^{\prime} j^{\prime \prime}} \equiv E\left(L_{j^{\prime}, t}-L_{j^{\prime \prime}, t}\right)$ for all $j^{\prime}, j^{\prime \prime} \in M^{0}$, a finite initial collection of forecasting model. With model $j^{\prime}$ preferred to model $j^{\prime \prime}$ when $\nu_{j^{\prime} j^{\prime \prime}}$ $<0$, define the set of superior models as: $M^{*} \equiv\left\{j^{\prime} \in M^{0}: \nu_{j^{\prime} j^{\prime \prime}} \leq 0 \quad \forall j^{\prime \prime} \in\right.$ $\left.M^{0}\right\}$.

With the objective of determining $M^{*}$, the test procedure estimates, $M_{1-\alpha}^{*}$, of confidence set at level, $\alpha$, through a sequence of significance tests with null hypothesis, $H_{0, M}: \nu_{j^{\prime} j^{\prime \prime}}=0$ for all $j^{\prime}, j^{\prime \prime} \in M$ and $M \subset M^{0}$. We denote the alternative hypothesis, $H_{1, M}: \nu_{j^{\prime} j^{\prime \prime}} \neq 0$ for all $j^{\prime}, j^{\prime \prime} \in M$. Therefore, with the selection process of the superior model starting with the allocation of the initial set of models $M^{0}$ to the set $M$, if the null hypothesis that the models are equally good is rejected, an elimination rule is employed to remove an inferior model from the set of models. This process is then repeated until it reduces the coverage ratio, $(1-\alpha)$, below the specified confidence level. Hence, when the null-hypothesis is statistically not rejected at the level, $\alpha$, the remaining set of models is the MCS, $M_{1-\alpha}^{*}$. Consequently, MCS procedures delete a model only if it is found to be significantly inferior to another model.

Table 8 presents the results of MCS for the collection of model candidates, OLS, SVR with Linear kernel function, SVR with Polynomial kernel function, and SVR with RBF kernel function. From Table 8, there is an evidence that 
the out-of-sample forecasting confidently identifies superior predictive accuracy of SVR model-based forecasts over OLS model. MCS identifies SVR model with RBF kernel function from a collection of model candidates, OLS, SVR with Linear kernel function, SVR with Polynomial kernel function, and SVR with RBF kernel function, as the best model with a given level of confidence. Additionally, Table 8 ranks the model's forecasts ordered by MCS p-value, with the SVR model with RBF kernel function more likely to generate the most accurate forecasts listed first, SVR model with Polynomial kernel function listed second, SVR model with Linear kernel function listed third, and finally OLS model.

Table 8: Ranking of SVR and OLS models

\begin{tabular}{|l|l|l|}
\hline Rank & Model & $\mathrm{P}_{M C S}$ \\
\hline 1 & SVR-RBF & $1.000^{* * *}$ \\
2 & SVR-Polynomial & $0.130^{*}$ \\
3 & SVR-Linear & 0.070 \\
4 & OLS & 0.050 \\
\hline
\end{tabular}

The third column reports MCSp-values for a model at hand, with*,**,and***identifying respectively the forecasts $M_{75}^{*}, M_{50}^{*}$, and $M_{25}^{*}$. SVR-Linear: SVR model with Linear kernel function. SVRPolynomial: SVR model with Polynomial kernel function. SVRRBF: SVR model with RBF kernel function.

\section{Challenges and Conclusions}

The out-of-sample evaluation of capital adequacy requirements on economic efficiency measures of U.S Commercial and Domestic banks has been addressed in this paper using a two-step approach analysis. First, economic efficiency measures are estimated using the nonparametric DEA model. Second, this paper examines the application of OLS and SVR models to forecast the performance of economic efficiency measures using capital adequacy requirements, in addition to regulatory, macroeconomics, and bank's characteristics exogeneous variables. Our sample consists of 10,380 December quarterly observations of U.S Commercial and Domestic banks covering the period of 2008 through 2019.

Henceforth, a coherent framework for producing a set of highly accurate models for forecasting the economic efficiency measures is presented in a threestep process. First, an approach for setting robust parameter values for SVR model with Linear, Polynomial, and RBF kernel functions while accounting for auto-correlation is conducted. Second, the out-of-sample forecast of SVR model with Linear, Polynomial, and RBF kernel functions is compared to the out-ofsample forecast of OLS model. Finally, our paper adopts the MCS test to select a subset of most accurate models among, OLS, SVR with Linear kernel function, SVR with Polynomial kernel function, and SVR with RBF kernel function.

Our results show that with a small set of predictors limited to the capital adequacy requirements, state gross domestic products, Basel Accord III and bank's size, SVR model with Linear, Polynomial, and RBF kernel functions outperform the linear-regression-based OLS model. We provide evidence that MCS identifies a relatively small set of SVR model with a superior out-of-sample forecasting ability in economic and statistical terms relative to the classical OLS model utilized in the literature. Hence, our results provide direct evidence that 
highly flexible SVR model with Linear, Polynomial and RBF kernel functions provides an alternative, promising technique and may be better suited than linear models, routinely employed in the literature. Furthermore, our approach accommodates novel economic applications characterized by serially correlated data and can be generalized to other markets.

There are, however, limitations that future researchers could improve. First, SVR model allow for testing of many kernel functions, while this study is limited to only the three most common in the literature. Another limitation is the length of the periods of historical banks considered. Future studies could expand the time frame and thus, evaluate the impact of 2007-2008 financial crisis. Finally, future studies could incorporate regional classification of the U.S Domestic and Commercial banks depending on the twelve federal districts.

\section{Financial disclosure}

- Funding: This study received no funding.

\section{Ethical statements}

- Research involving Human Participants and/or Animals: No.

- Disclosure of potential conflicts of interest: The authors declare that they have no conflict of interest.

- Informed consent: No informed consent was needed since this study does not Human Participants and/or Animals.

\section{Reference}

Anderson, G., and Audzeyeva, A. (2019). A Coherent Framework for Predicting Emerging Market Credit Spreads with Support Vector Regression, Finance and Economics Discussion Series-074. Washington: Board of Governors of the Federal Reserve System, https://doi.org/10.17016/FEDS.2019.074.

Assaf, A., Berger, A., Roman, R., and Tsionas, M. (2019). Does efficiency help banks survive and thrive during financial crises? Journal of Banking and Finance, 106, 445470.

Banker, R., Charnes, A., and Cooper, W. (1984). Some models for estimating technical scale inefficiencies in data envelopment analysis. Management Science, Vol. 30, pp. 1078-1092.

Barth, R., Caprio, G. and Levine, R. (2004). Bank regulation and supervision: What works best? Journal of Financial Intermediation, Vol. 13 No. 2, pp. 205-248.

Barth, J., Lin, C., Ma, Y., Seade, J., and Song, M. (2013). Do bank regulation, supervision and monitoring enhance or impede bank efficiency? Journal of Banking and Finance, Vol. 37 No. 8, pp. 2879-2892.

Berger, N., and Bonaccorsi, E. (2006). Capital structure and firm performance: A new approach to testing agency theory and an application to the banking industry. Journal of Banking and Finance, Vol. 30 No. 4, pp. 1065-1102. 
Brabanter, K.D., Brabanter, J., Suykens, J., Moor, B. (2011). Kernel regression in the presence of correlated errors. Journal of Machine Learning Research, Vol. 12, pp. 1955-1976.

Burman, P., Chow, E., and Nolan, D. (1994). A cross-validatory method for dependent data. Biometrika, Vol. 84, pp. 351-358.

Carmack, P., Spence, J., Schucany, W., Gunst, R., Lin, Q., \& Haley, R. (2009). Forecasting cross validation. Journal of Computational and Graphical Statistics, Vol. 18 No. 4, pp. 879-893.

Casu, B., and Girardone, C. (2002). A Comparative Study of the Cost Efficiency of Italian Bank Conglomerates. Managerial Finance, 28, 3-23.

Charnes, A., Cooper, W., and Rhodes, E. (1978). Measuring the efficiency of decision-making units. European Journal of Operational Research, Vol. 2 No. 6, pp. 429-444.

Chortareas, E., Girardone, C, and Ventouri, A. (2012). Bank supervision, regulation, and efficiency: Evidence from the European Union. Journal of Financial Stability, Vol. 8 No. 4, pp. 292-302.

Choudhury, S., Ghosh, S., Bhattacharya, A., Fernandes, K., and Tiwari, M. (2014). A real time clustering and SVM based price-volatility prediction for optimal trading strategy. Neurocomputing, Vol. 131 No. 1, pp. 419-426.

Cortes, C., and Vapnik, V. (1995). Support Vector Networks. Machine Learning, Vol. 20, pp. 273-297.

Demirguc-Kunt, A., Detragiache, E. and Tressel, T. (2008). Banking on the principles: Compliance with Basel core principles and bank soundness. Journal of Financial Intermediation, Vol. 17, pp. 511-542.

Diebold, F., and Mariano, R. (1991). Comparing Predictive Accuracy I: An Asymptotic Test. Discussion Paper 52, Institute for Empirical Macroeconomics, Federal Reserve Bank of Minneapolis.

Diebold, F., and Mariano, R. (1995). Comparing Predictive Accuracy. Journal of Business and Economic Statistics, Vol. 13, pp. 253-263.

Ding, Y., Song, X., and Zen, Y. (2008). Forecasting financial condition of Chinese listed companies based on support vector machine. Expert Systems with Applications, Vol. 34, pp. 3081-3089.

Dong, Y., Hamilton, R., and Tippett, M. (2014). Cost efficiency of the Chinese banking sector: A comparison of stochastic frontier analysis and data envelopment analysis. Economic Modelling, Vol. 36, pp. 298-308.

Drake, M., Hall, M., and Simper, R. (2006). The Impact of Macroeconomic and Regulatory Factors on Bank Efficiency: A nonparametric Analysis of Hong Kongs Banking System. Journal of Banking Finance, Vol. 30, pp. 1443-1466.

Färe, R., Grosskopf, S. and Lovell, K. (1985). The Measurement of Efficiency of Production, KluwerNijhoff, Boston, pp. 170.

Gorton, B., and Metrick, A. (2010). Securitized banking and the run on repo. Yale ICF Working Paper No. 09-14.

Gunduz, Y., and Uhrig-Homburg, M. (2011). Predicting credit default swap prices with financial and pure data-driven approaches. Quantitative Finance, Vol. 11, pp. 1709-1727.

Hansen, P. (2005). A test for superior predictiveability. Journal of Business \& Economic Statistics, Vol. 23, pp. 365-380.

Hansen, P., and Lunde, A. (2010). Mulcom 2.0, econometric toolkit for multiple comparisons. 
Hansen, P., Lunde, A., and Nason, J. (2011). The model confidence set. Econometrica, Vol. 2 No. 79, pp. 453-497.

Hart, J. \& Lee, C. (2005). Robustness of one-sided cross-validation to autocorrelation. Journal of Multivariate Analysis, Vol. 92 No. 1, pp. 77-96.

Hart, J. \& Yi, S. (1998). One-sided cross-validation. Journal of the American Statistical Association, Vol. 93 No. 442, pp. 620-630.

Harvey, C., and Liu, Y. (2019). Cross-sectional alpha dispersion and performance evaluation. Journal of Financial Economics, Vol. 134 No. 2, pp. 273-296.

Hoff, A. (2007). Second stage DEA: Comparison of approaches for modelling the DEA score. European Journal of Operational Research, Vol. 181 No. 1 , pp. $425-435$.

Holmstrom, B. and Tirole, J.(1997). Financial intermediation, loanable funds, and the real sector. The Quarterly Journal of Economics, Vol. 112 No. 3, pp. 663-691.

Hwang, S., and Kao, T. (2008). Using two-stage DEA to measure managerial efficiency change of non-life insurance companies in Taiwan. International Journal of Management and Decision Making, Vol. 9 No. 4, pp. 377-401.

Manahov, V., Hudson, R., and Gebka, B. (2014). Does high frequency trading affect technical analysis and market efficiency? And if so, how? Journal of International financial markets, Vol. 28 No. 1, pp. 131-157.

Mehran, H. and Thakor, A. (2011). Bank capital and value in the cross-section. Review of Financial Studies, Vol. 24 No. 4, pp. 1019-1067.

Min, J., and Lee, Y. (2005). Bankruptcy prediction using support vector machine with optimal choice of kernel function parameters. Expert Systems with Applications, Vol. 28, pp. 603-614.

Nayak, R., Mishra, D., and Rath, A. (2015). A Nave SVM-KNN based stock market trend reversal analysis for Indian benchmark indices. Applied Soft Computing, Vol. 35 No. 1, pp. 670-680.

Pasiouras, F., Tanna, S., and Zopounidis, C. (2009). The impact of banking regulations on banks' cost and profit efficiency: Cross country evidence. International Review of Financial Analysis, Vol. 18 No. 5, pp. 294-302.

Patel, J., Shah, S., Thakkar, P., and Kotecha, K. (2015). Predicting stock market index using fusion of machine learning techniques. Expert Systems with Applications, Vol. 42 No. 4, pp. 2162-2172.

Pessarossi, P., and Weill, L. (2015). Do capital requirements affect cost efficiency? Evidence from China. Journal of Financial Stability, Vol. 19, pp. $119-127$.

Racine, J. (2000). Consistent cross-validatory model-selection for dependent data: hv-block cross-validation. Journal of Econometrics, Vol. 99, pp. 39-61.

Rosman, R., Wahab, N., and Zainol, Z. (2014). Efficiency of Islamic banks during the financial crisis: An analysis of Middle Eastern and Asian countries. Pacific-Basin Finance Journal, Vol. 28, pp. 76-90.

Sakouvogui, K. (2020a). Impact of liquidity and solvency risk factors on the variance of cost efficiency measures. Managerial Finance, Vol. 46 No. 7, pp. 883-895.

Sakouvogui, K. (2020b) A comparative approach of stochastic frontier analysis and data envelopment analysis estimators: evidence from banking system. Journal of Economics Studies, Vol. ahead-of-print No. ahead-of-print. 
Sakouvogui, K., and Shaik, S. (2020). Impact of financial liquidity and solvency on cost efficiency-Evidence from US Banking System. Studies in Economics and Finance, Vol. ahead-of-print No. ahead-of-print.

Sakouvogui, K., Shaik, S., and Addey, K. (2020). Cluster-Adjusted DEA Efficiency in the presence of Heterogeneity: An Application to Banking Sector. Open Economics, Vol. 3 No. 1, pp. 50-69.

Sakouvogui, K., and William, N. (2019). Robust CAPM Estimation through Cross Validation. The Journal of Financial Data Science, Vol. 1 No. 2, pp. 153-167.

Sherman, D. and Gold, F. (1985). Bank branch operating efficiency: Evaluation with data envelopment analysis. Journal of Banking and Finance, Vol. 9 No. 2, pp. 297-316.

Thagunna, S., and Poudel, S. (2013). Measuring bank performance of Nepali banks: A data envelopment analysis (DEA) perspective. International Journal of Economics and Financial Issues, Vol. 3 No. 1, pp. 54-65.

Vapnik, V. (1995). The nature of statistical learning theory. Springer-Verlag NewYork, Inc.

White, H. (2000). A reality check for data snooping. Econometrica, Vol. 68 No. 5, pp. 1097-1126. 
Figures

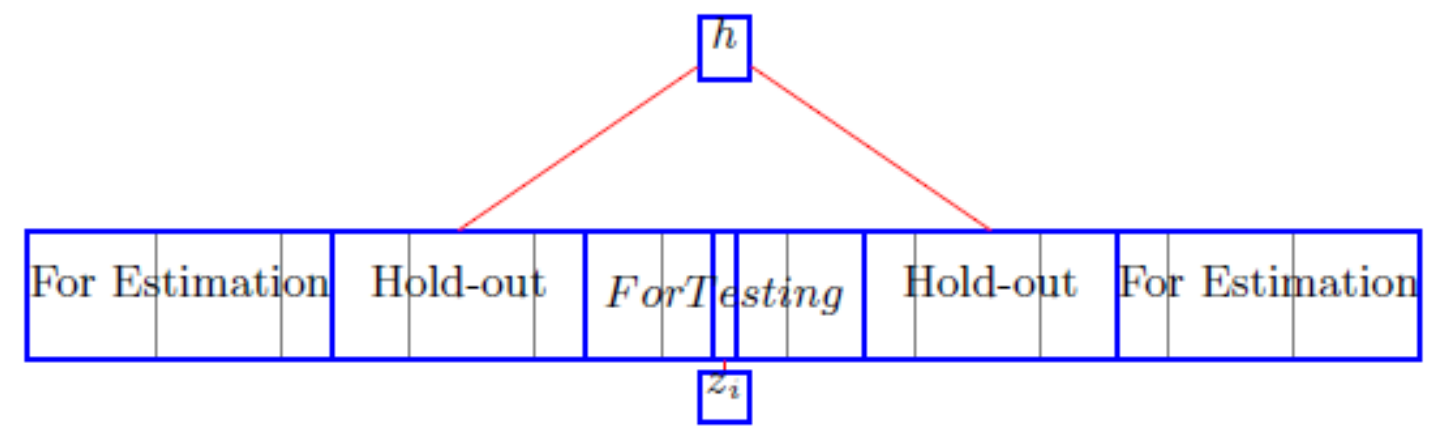

Figure 1

H-block cross-validation
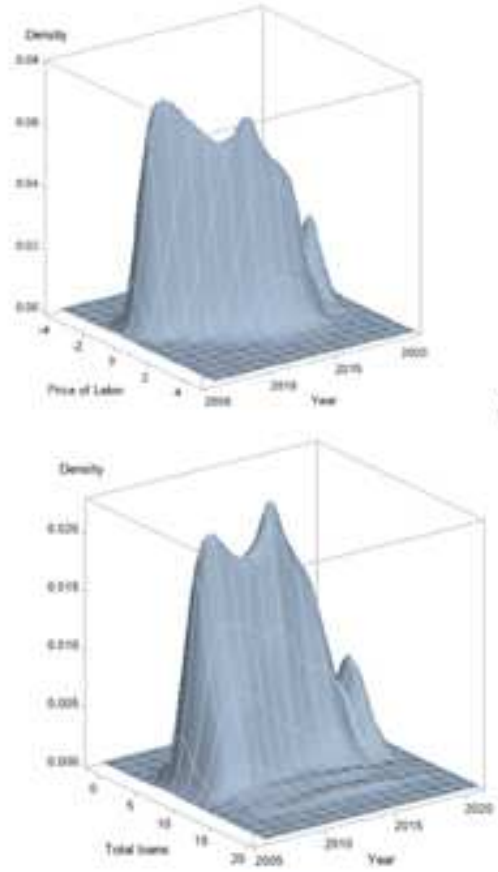

( $w_{1}$ and year)

( $y_{1}$ and year)

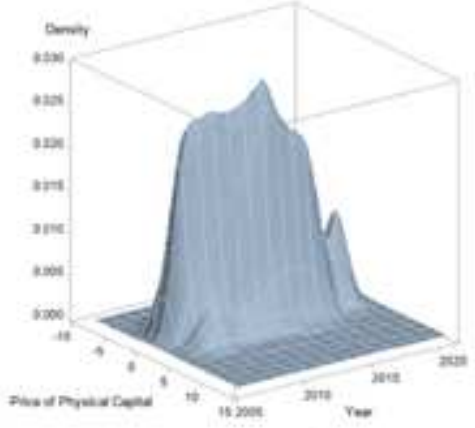

( $w_{2}$ and year)

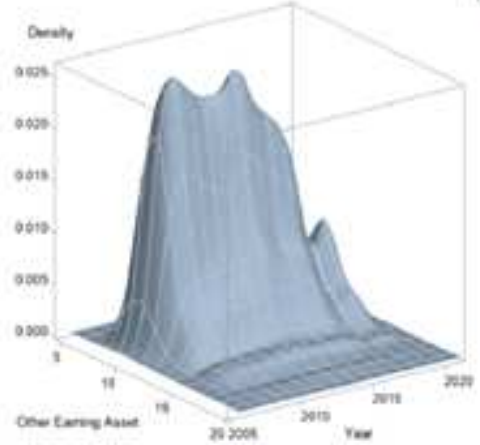

( $y_{2}$ and year)

Figure 2

Distribution of input prices and output quantities across years. 

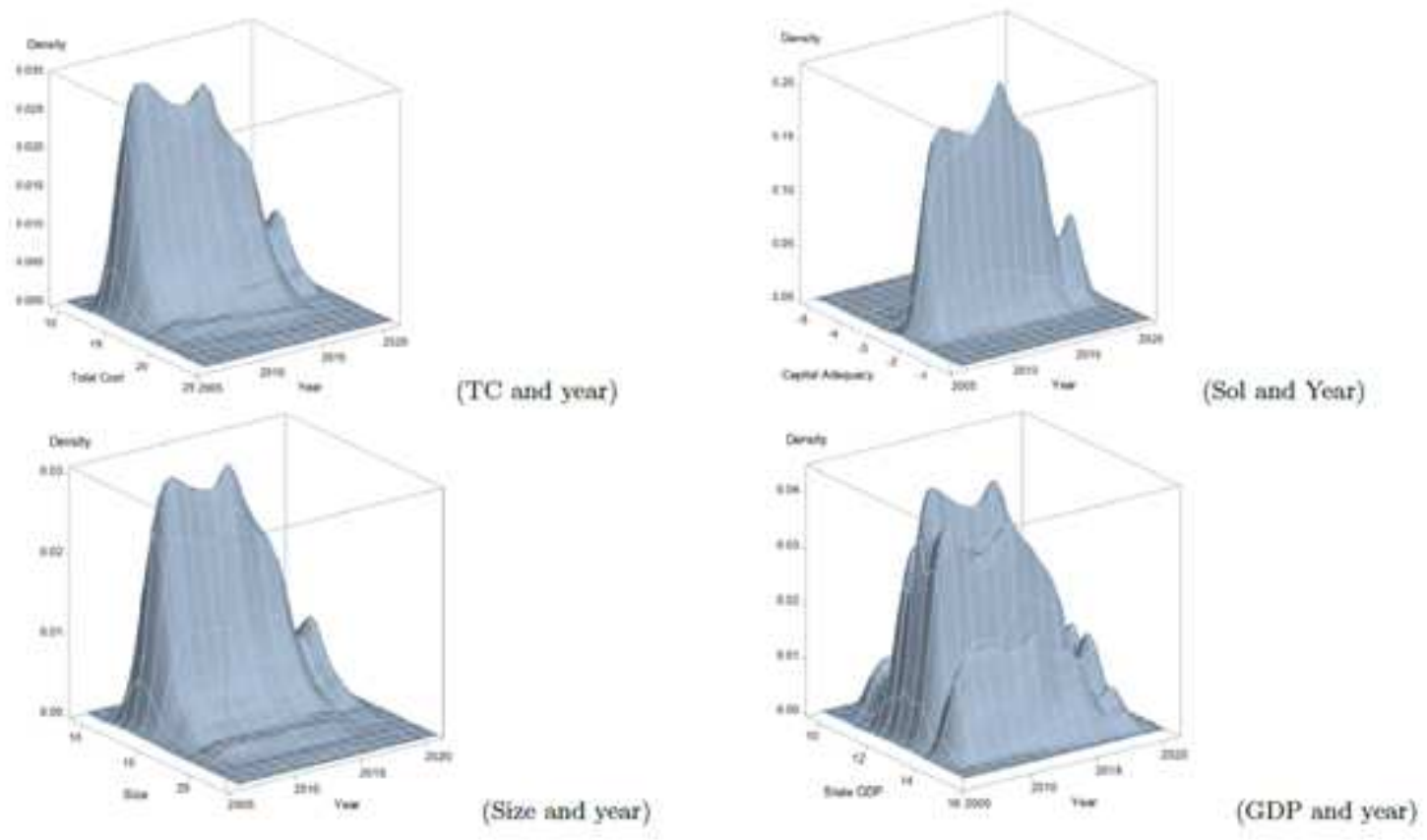

Figure 3

Distribution of log of total cost and exogeneous variables across years 

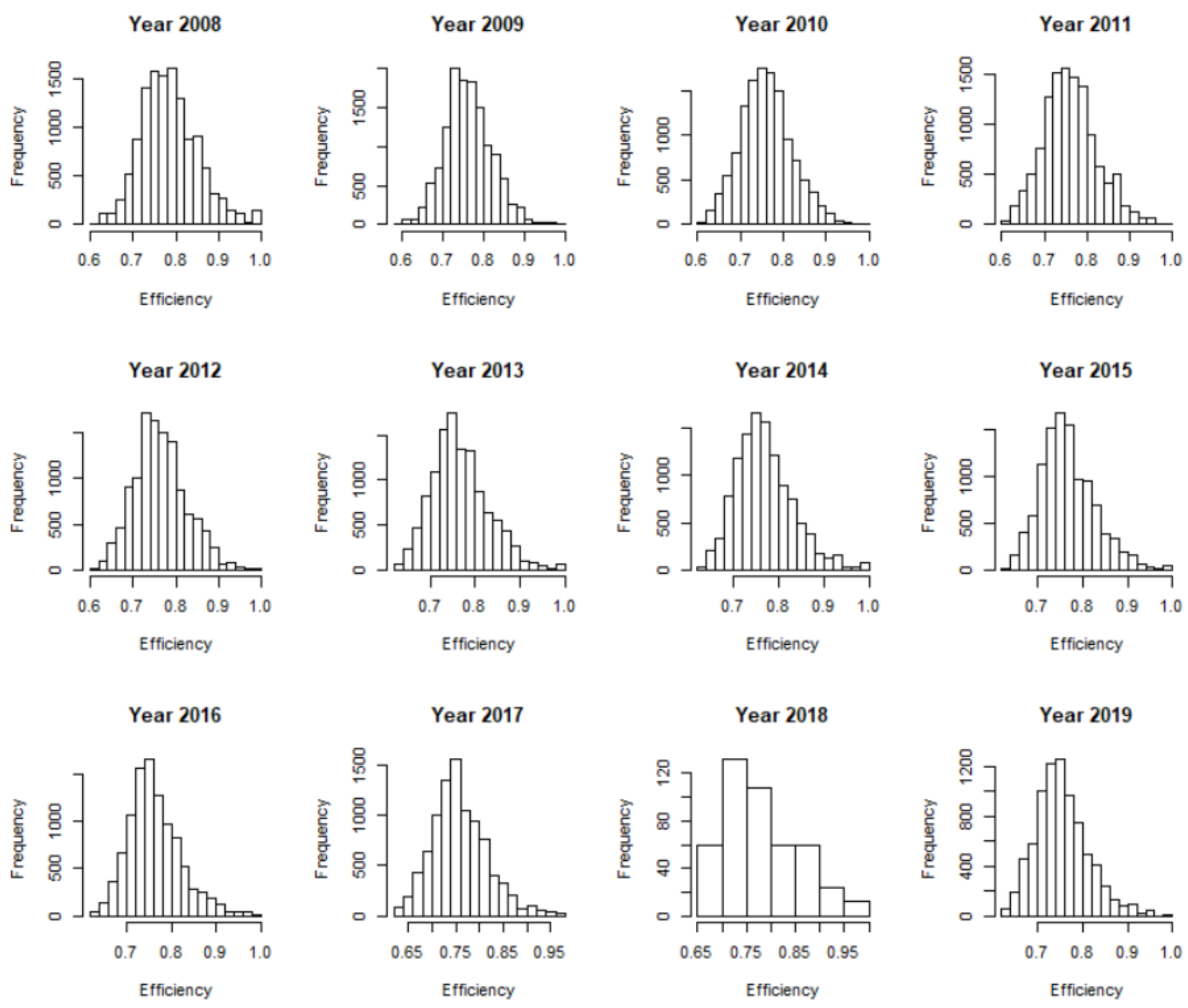

Figure 4

Economic efficiency measures under CRS assumption 

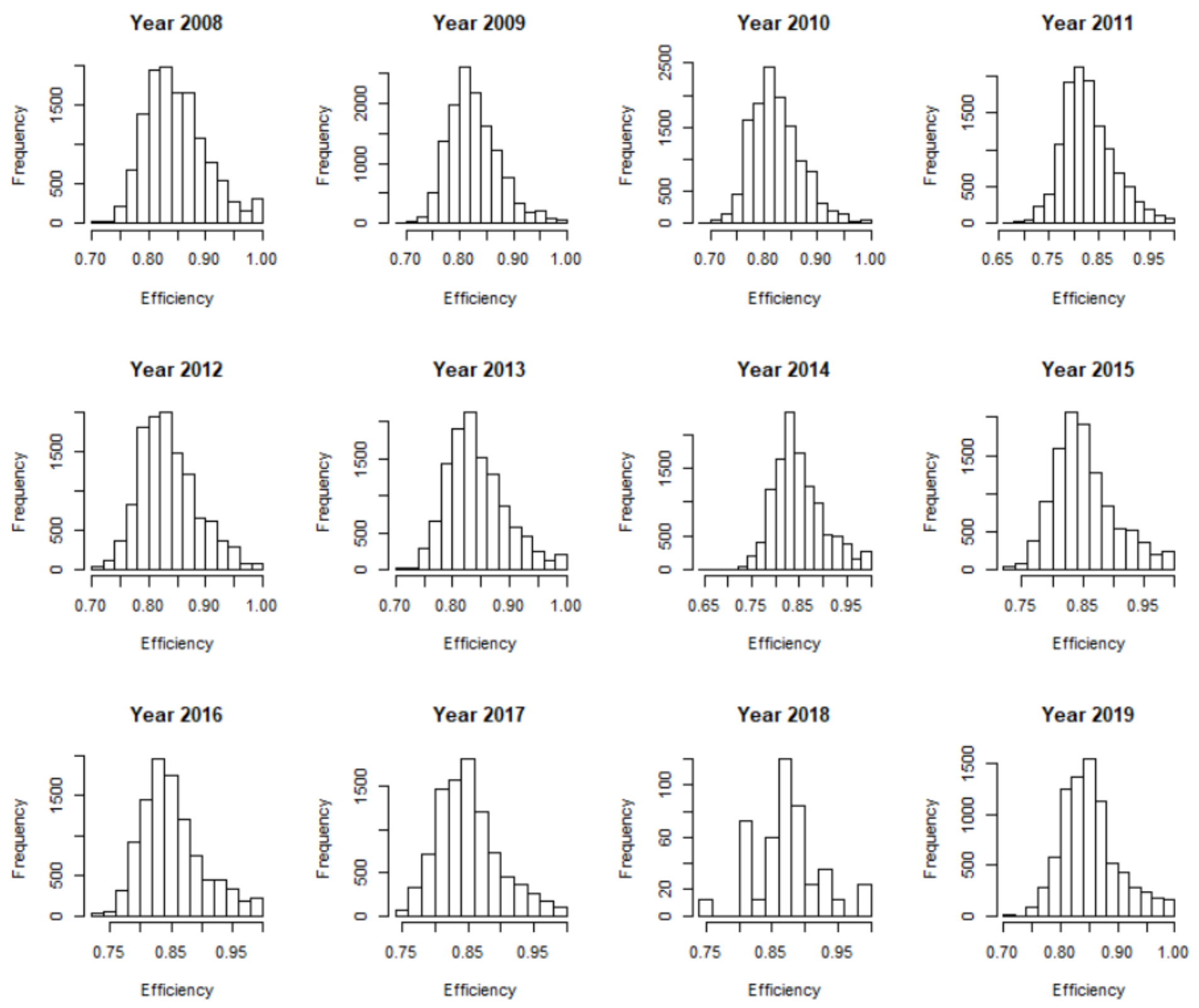

Figure 5

Economic efficiency measures under VRS assumption 


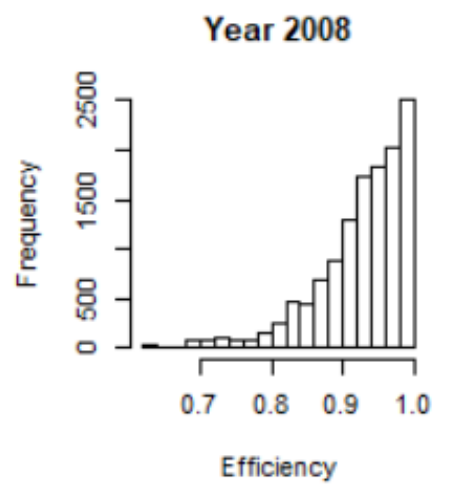

Year 2009

Year 2010

Year 2011
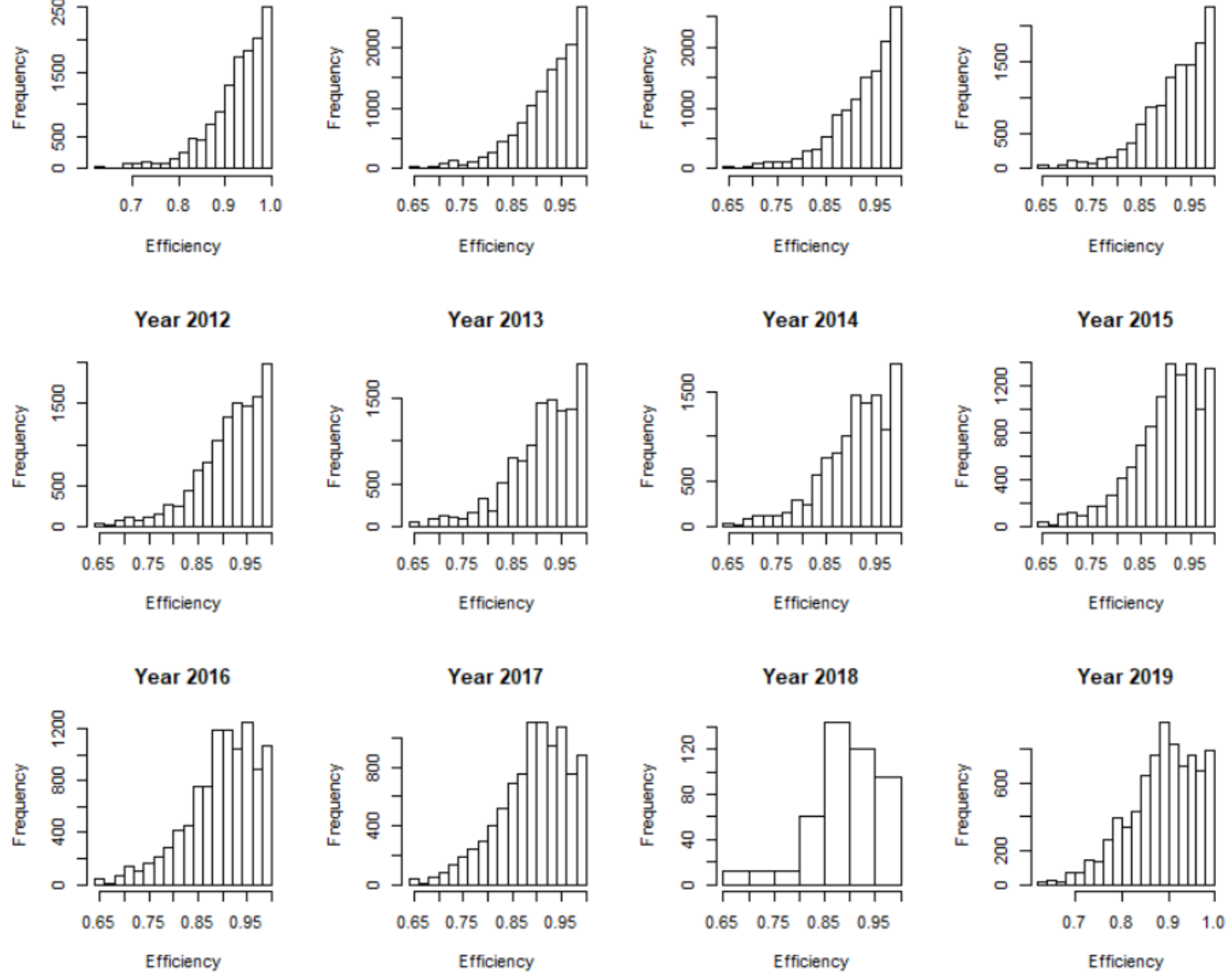

Figure 6

Economic efficiency measures under scale assumption 

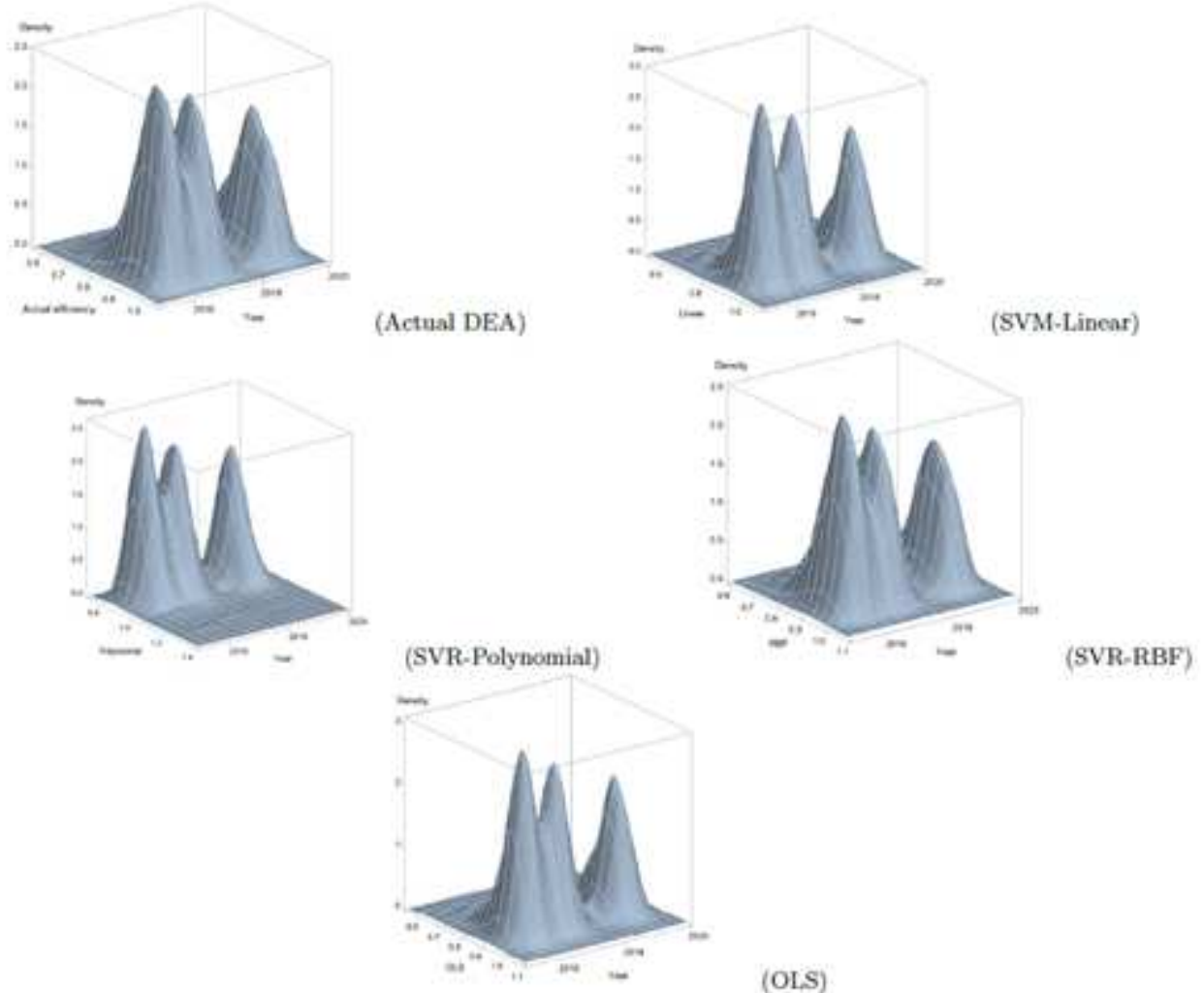

(OLS)

Figure 7

Prediction of economic efficiency measures 